\title{
4. FUNKTIONEN VON WUNDERERZAHLUNGEN IN GUIBERTS TEXTEN
}

Nachdem in einem ersten Schritt thematisiert wurde, wie Guibert und seine Umgebung Ereignisse als Wunder interpretierten und in einem weiteren, in welchen Zusammenhängen und in welchen Gruppen über Wunder und Wundererzählungen kommuniziert wurde, wird nun die Stellung, die Funktionen und die Deutungen von Wundererzählungen innerhalb der Werke Guiberts de Nogent im Zentrum der Betrachtung stehen. Mit den Worten von Gabrielle M. Spiegel soll hier der Moment des Einschreibens betrachtet werden ${ }^{1}$. Das heißt, der Moment, in dem den Erzählungen Bedeutungen innerhalb von Guiberts Texten zugeordnet werden. Der Moment also, in dem Guibert Wundererzählungen in seine Texte einfügt und diese als Elemente eines größeren Textganzen in neue Zusammenhänge stellt.

$\mathrm{Da} \beta$ Bedeutungen von Wundererzählungen in Guiberts Texten nicht immer eindeutig, sondern mehrschichtig sind, ist bei so komplexen literarischen Texten, wie sie Guibert verfaßt hat, zu erwarten. Oft aber bietet Guibert selbst Deutungen von Wundererzählungen, die in diesem Kapitel im Mittelpunkt stehen. Diese Deutungen können die Zusammenhänge der Wundererzählungen mit den größeren Themen der Werke offenlegen und so wiederum Hinweise auf neue Deutungsebenen dieser Werke sein.

1 SPIEgel, Geschichte, S. 192: „Diese Vorstellung von Einschreiben (oder dem Festlegen von Bedeutungen) sollte nicht mit dem traditionellen ,Schreiben` oder ,Aufzeichnen` verwechselt werden. Es geht hier mehr um die Frage der Auswahl, der Entscheidung, und des Handelns zur Schaffung der sozialen Realität des Textes, eine Realität, die sowohl innerhalb< als auch >außerhalb< des jeweils durch den Text Dargestellten existiert, durch das Miteinbezogene oder Ausgeblendete, Verzerrte oder Betonte." 


\subsection{Wundererzählungen in den Monodiae}

\subsubsection{Stellung der Wundererzählungen}

Die autobiographische Schrift, die Guibert mit Monodiae bezeichnet hat, ist im heutigen Zustand in drei Bücher eingeteilt ${ }^{2}$. Um die Stellung und Funktion der Wundererzählungen zu betrachten, muß mit der Struktur des Textes in der Edition Labande als Grundlage gearbeitet werden, im Bewußtsein, daß Textteile oder gar ein ganzes Buch fehlen können. Die heutige Einteilung in Bücher ist vor allem für den Übergang vom ersten zum zweiten Buch zu rechtfertigen, da im letzten Satz des ersten Buches vom zweiten Buch gesprochen wird $^{3}$. Der Beginn des dritten Buchs wird durch den Themenwechsel und den einleitenden Satz sichtbar. Mit diesem Satz führt Guibert das folgende Thema ein: die Tragödien der Leute von Laon4.

In den Monodiae muß von einem relativ breiten Verständnis von Wundererzählungen ausgegangen werden. So werden Versuchungen durch Dämonen auch dazu gezählt, denn oft sind diese und Rettung der Versuchten durch den Willen Gottes kombiniert 5 . Eine Betrachtung des Aufbaus des Werkes zeigt, daß die Erzählungen meist gruppiert stehen, teilweise gemeinsam mit anderen kurzen Texteinheiten, die nicht im engen Sinne wunderbares Geschehen thematisieren. Dieser Aufbau ist in der Übersicht auf S. 163 kurz zusammengefaßt, die Gruppen von Wundererzählungen sind hervorgehoben.

Diese Zusammenstellung zeigt, daß in allen drei Büchern der Monodiae Wundererzählungen enthalten sind. Auffällig ist, daß sich diese zum Schluß jedes Buches häufen. Auch die Wundererzählungen, die innerhalb der einzelnen Kapitel stehen, sind oft gruppiert. In diesen Gruppen werden nicht ausschließlich Wundererzählungen referiert. So in der ersten Gruppe im ersten Buch, das von Guiberts Werdegang, seiner Kindheit und Jugend und auch von seiner Mutter handelt. Vor der Schilderung des Rückzugs seiner Mutter von der Welt erzählt Guibert mehrere Fälle von Konversionen Adeliger (Kap. 8-11). So beschreibt er die Konversion des Evrard von Breteuil, des Simon von Crépy und die Gründung der Chartreuse in der Diözese Grenoble durch Bruno ${ }^{6}$.

2 Zur schlechten Handschriftengrundlage und zur unsicheren Einteilung des Werkes siehe oben, S. 28-31.

${ }^{3}$ GuiberT de Nogent, Autobiographie, I, 26, S. 208: Haec de iis, quae in monasterio viderim aut audierim dixisse sufficiat. At deinceps, cum superius de illa nostra qualicunque electione dixerimus, quis ipse locus, qualiter institutus, quas antiquitates habuerit, ad quem translati Deo auctore sumus, alterius libelli initio attingamus.

${ }_{4}$ Ibid. III, 1, S. 268: De Laudunensibus, ut spopondimus, jam modo tractaturi, imo Laudunensium tragoedias acturi [...].

5 Siehe dazu auch S. 12.

6 Guibert de Nogent, Autobiographie, I, 11, S. 62-72. Zu Evrard von Breteuil Iogna-Prat, Evrard de Breteuil; zu Simon von Crépy Lauwers, Simon de Crépy. 
Tab. 1: Inhaltsübersicht der Monodiae ${ }^{7}$

\section{Buch: autobiographischer Teil}

Kap. 1-2: $\quad$ Sündenbekenntnis, Lob der Mutter

Kap. 3-7: Kindheit, Jugend

Kap. 8-11: Darstellung der Konversion verschiedener Adeliger, Strafwunder im

Gefolge des Manasses von Reims, Klostergründungen

Kap. 12-14: Seine Mutter, deren Rückzug von der Welt

Im Kap. 13: Dämonenvision der Mutter

Kap. 15: Mit 12 Jahren Eintritt ins Kloster Saint-Germer-de-Fly

Beispiele für Aktivität des Teufels gegen frisch Konvertierte in Beauvais

Kap. 16-19: Als Mönch in Fly bis zur Wahl zum Abt in Nogent

Kap. 20-26: Mönchsgeschichten aus Fly und Umgebung:

- Teufelsgeschichten (gute Mönche widerstehen, geizige Mönche werden bestraft)

- Blitzschläge im Kloster (Blitz als Strafe)

- Tod eines sündigen Mönchs, leere Gräber, Totenvision einer Nonne

- Weitere Bestrafung von Sündern (v. a. Mönchen) durch Teufel

- Zauberei, Teufelsanrufung

2. Buch: im Kloster Nogent

Kap. 1-3: Geschichte des Klosters Nogent

Im Kap. 1: Inhalt einer Schrift: Gründungslegende des Klosters

Kap. 4: $\quad$ Tod der Mutter

Kap. 5: Jüdischer Mönch in Fly

Wunderbares Zeichen bei der Bekehrung des Judenknaben, zwei

Geschichten von Priestern, die vom Teufel versucht werden

Kap. 6: Weitere Geschichten: Teufelanrufung durch Diener, »drei Fieber«,

Eintritt eines vom Teufel gequälten Klerikers ins Kloster

3. Buch: Ereignisse in Laon

Kap. 1-11: Darstellung der Amtsführung der Bischöfe von Laon, Mord in der Kathedrale von Laon, Aufstand in der Stadt, Mord des Bischofs, Zerstörung der Kathedrale

Im Kap. 9: Nach dem Brand von Laon bleibt die Nacht hell

Kap. 12-13: Auswahl von Marienwundern, die auf den Kollektenreisen der Kleriker von Laon geschehen

Kap. 14-17: Darstellung der Ereignisse in Laon, Adelige in der Region, Häresien

Im Kap. 15: Dieb Ansellus wird durch Maria der Strafe zugeführt

Im Kap. 16: Schlechter Tod des Johannes von Soissons

Kap. 18-20: Sog. »Wunderanhang«: Wunder und Teufelsgeschichten aus verschiedenen Zusammenhängen, siehe separate Zusammenstellungen S. 168-173.

Guibert geht nach der Darstellung seines Entschlusses, zum Mönchtum zu konvertieren (Kap. 15), ähnlich vor. Anschließend an die Beschreibung seiner eigenen Dämonenvision berichtet er von Dämonen, die auf ähnliche Weise einen jungen Mann quälten, der zum Mönchtum konvertieren wollte ${ }^{8}$. Am

7 Als Kapiteleinteilung wird diejenige der Edition Guibert DE Nogent, Autobiographie, übernommen.

8 Guibert DE Nogent, Autobiographie, I, 15, S. 118-120. 
Ende des ersten Buches, nach dem Bericht seiner Wahl zum Abt von Nogent, schließt Guibert die Geschichte seiner Kindheit und seiner Zeit als Mönch in Saint-Germer-de-Fly mit einer Gruppe von Wundererzählungen ab, von welchen er in diesem Kloster Kenntnis erlangt hatte9.

Das zweite Buch ist auffällig viel kürzer als die beiden anderen, die in der Edition Labande $42 \%$, beziehungsweise $45 \%$ des edierten Textes umfassen ${ }^{10}$. Im ersten Kapitel des zweiten Buches referiert Guibert als Gründungslegende seines Klosters eine wunderbare Reliquienreise eines britischen Königs. Die große Gruppe von Wundererzählungen findet sich jedoch am Ende des Buches, das zu großen Teilen der Geschichte von Nogent gewidmet ist. Diese Gruppe von Erzählungen nimmt etwas mehr als ein Drittel des Buches ein.

Im dritten Buch, der Darstellung der Tragödie der Einwohner von Laon, stehen die Wundererzählungen wieder an ähnlicher Position. So findet sich eine einzelne Erzählung nach den Ausführungen zum Brand der Kathedrale infolge des städtischen Aufstands ${ }^{11}$. Guibert fügt eine größere Gruppe von Wundern, die sich auf der Reliquienreise der Kleriker von Laon ereignet hatten, an die Darlegung des städtischen Aufstandes, des Bischofsmordes und des Wesens des Bischofs und der Stadtbewohner an (Kap. 12 und 13) ${ }^{12}$. Anschließend an diese Gruppe von Erzählungen folgt im Text die Wahl eines neuen Bischofs in Laon. Auch die Erzählung über den Dieb Ansellus ist als ausführliches Beispiel der Schlechtigkeit der Leute von Laon erzählt (Kap. 15), bevor Guibert die Situation in der Nachbardiözese Soissons thematisiert. Die Geschichte des schlechten Todes des Grafen Johannes von Soissons markiert den Übergang zur Beschreibung einer Häresie im Soissonnais (Kap. 17). Anschließend folgt wiederum eine Gruppe von Wundererzählungen, die den Schlu $ß$ des Buches kennzeichnet.

Dabei fällt auf, daß die Wundererzählungen immer an Wendepunkten oder Brüchen des hauptsächlichen Erzählstranges eingefügt werden ${ }^{13}$. Dies am deutlichsten im ersten Buch: Vor dem Entschluß von Guiberts Mutter zum

${ }^{9}$ Ibid. I, 19, S. 168: Sed, quoniam in hac Flaviacensi ecclesia sub Deo parente et beati Geremari, loci ejusdem conditoris, patrocinio coaluisse nos diximus, quaedam, / quae ibidem audivimus fierique vidimus, dignum ut memoriae tradamus.

10 Ibid. Einleitung, S. XVI. Zu dieser Unausgewogenheit der Bücher siehe RubensteIN, Guibert of Nogent, S. 62.

11 Guibert De Nogent, Autobiographie, III, 9, S. 356.

$12 \mathrm{Zu}$ einzelnen Wundern auf dieser Reliquienreise siehe auch unten, S. 184-186. In der Handschrift BN lat. 12593 aus Corbie (siehe unten, S. 237) werden in einer Abschrift des Wunderbuchs des Hermann von Tournai der Bischofsmord und die Rekonziliation der Kathedrale als Initialen dargestellt (siehe Abb. 1 und 2)..

13 Siehe zur Wahrnehmung von Brüchen als Motor zur Selbstdarstellung HaHN, Biographie und Lebenslauf, S.98, der gerade das Bewußtsein anderer möglicher Verläufe des Lebensweges an solchen Bruchstellen als sehr wichtig für die Entstehung von Selbstdarstellungen erachtet. Dies stellt er in den Zusammenhang von Sündenbekenntnis und Beichte, die in den Monodiae eine wichtige Rolle spielen. Guibert spricht im ersten Buch oft von alternativen Möglichkeiten, so vom Leben in der Welt, das ihm seine Mutter angesichts des harten Schulunterrichts anbietet, GuIBERT DE NogEnT, Autobiographie, I, 6, 
Abb. 1: Initiale mit der Darstellung der Ermordung von Bischof Gaudry von Laon. Bibliothèque nationale de France, lat. 12593, fol. 33.

Abb. 2: Initiale mit der Darstellung der Rekonziliation der Kirche von Laon.

Bibliothèque nationale de France, lat. 12593, fol. 45v.
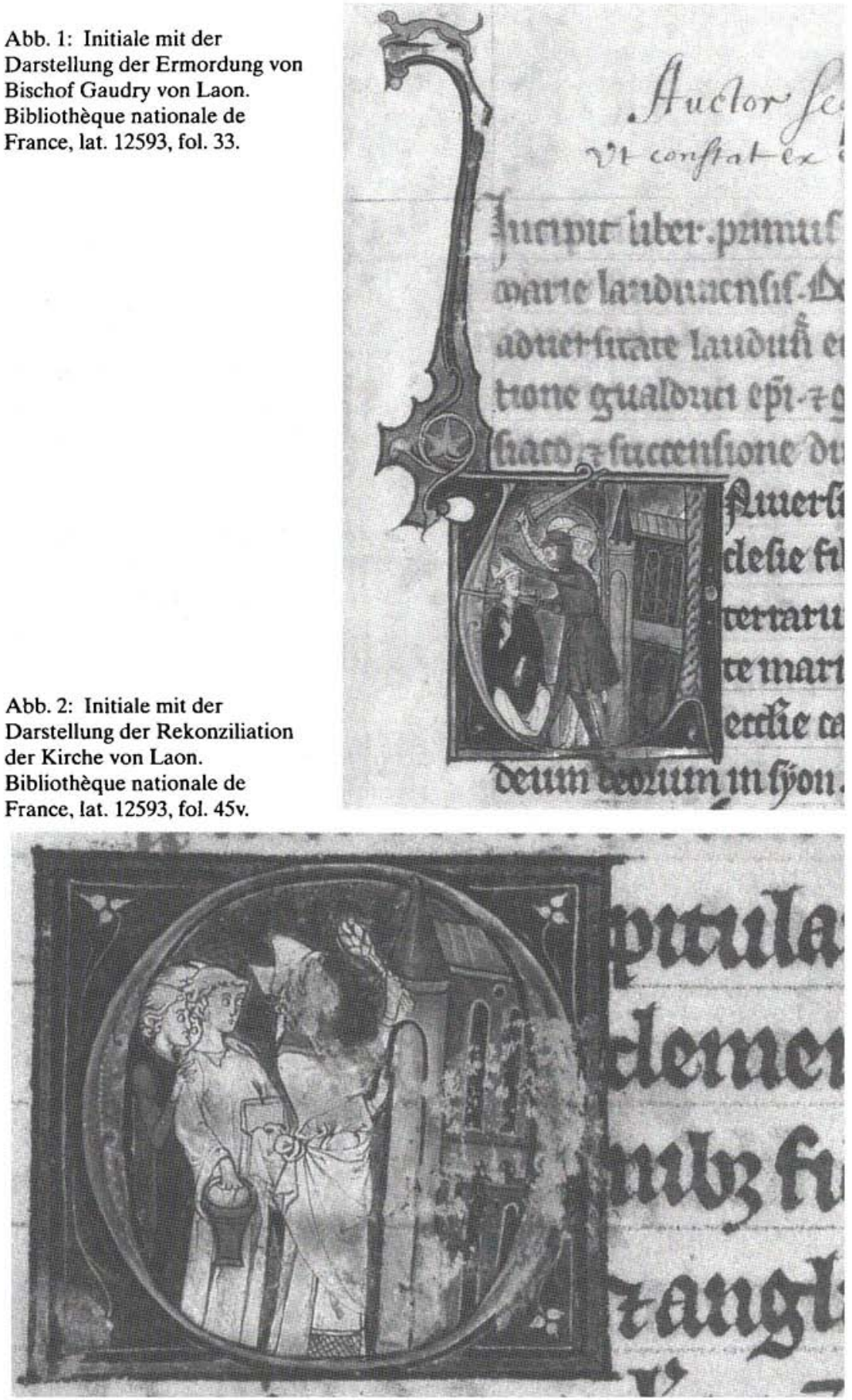
Rückzug von der Welt, nach Guiberts eigenem Entschluß zum Eintritt in die monastische Gemeinschaft, nach Guiberts Wahl zum Abt. Auch im dritten Buch sind die Wundererzählungen an Bruchstellen eingefügt: Sowohl der Brand der Kathedrale als auch die Wahl eines neuen Bischofs sind einschneidende Ereignisse im städtischen Leben. Danach öffnet Guibert den Blickwinkel und thematisiert die Ereignisse aus der Region.

\subsubsection{Funktionen von Wundererzählungen}

\section{Wundererzählungen als Exkurse}

Die Wundererzählungen nehmen in den Monodiae relativ breiten Raum ein. Sie machen etwa ein Viertel des gesamten überlieferten Textes aus. Sie haben für den Gesamttext eine wichtige Stellung und sollten nicht als bloße stilistische Randerscheinung gedeutet werden.

In den Monodiae funktionieren Wundererzählungen zumeist als Exkurse. Diese Erzählungen unterbrechen die Haupthandlung des jeweiligen Buches, unterstreichen sie in einer Aussage oder werden dieser auf eine weitere Art beigefügt ${ }^{14}$. Das Thema der Monodiae ist das Sündenbekenntnis. Dies wird deutlich zu Beginn von Guiberts Werk. Der erste Satz lautet: Confiteor, amplitudini tuae, Deus, infinitorum errorum meorum decursus, et creberrimos ad te miserationis internae, quos tamen inspirasti, recursus ${ }^{15}$.

Als Vorbild seiner autobiographischen Darstellung dienen Guibert die Confessiones des Augustin. Die Darstellung des Lebensweges ist bei Guibert aber eine andere als bei Augustin, der einen Weg hin zu Gott aufzeigt. Guibert hingegen schildert ein Hin und Her zwischen Gott und Sünde, eine Abfolge von Hinwendungen zu und Abwendungen von Gott. Guibert stellt sein Verhalten in verschiedenen Situationen entlang seines Lebenswegs chronologisch geordnet dar: als Knabe, als junger Mönch, als $\mathrm{Abt}^{16}$. Im ersten Buch wird neben Guiberts eigenem Verhalten auch das Verhalten von Guiberts Mutter als adeliger Witwe dargestellt. Auch für die Rolle von Guiberts Mutter wurden viele Analogien zur Rolle der Mutter Augustins festgestellt ${ }^{17}$. Im dritten Buch ist Guiberts eigenes Verhalten nur noch ein Thema unter vielen.

S. 40; oder auch von der wiederholten Suche nach einer Karrieremöglichkeit durch seine Familie, ibid. I, 7, S. 42-48; I, 19, S. 158-164.

14 Über die rhetorische Funktion von digressiones als Teile der narratio siehe LAUSBERG, Rhetorik, S. 187f.; WARD, Some Principles, S. $112 f$.

15 Guibert De Nogent, Autobiographie, I, 1, S. 2. Zu den Monodiae, die in der augustinischen Tradition stehen, siehe Amory, Confessional superstructure; Courcelle, Confessions; Hallenstein, Nachbildung; Misch, Geschichte der Autobiographie.

16 Rubenstein, Guibert of Nogent, S. 65 stellt fest, daß Guibert in seiner Erzählung des eigenen Lebens stark von seiner Genesis-Exegese geprägt ist. Er erzählt sein Leben ana$\log \mathrm{zu}$ einem christlichen Leben, wie er es in der Genesis erkannt hat.

17 Siehe dazu Misch, Geschichte der Autobiographie, S. 120f.; RöcKelern, Zwischen Mutter und Maria, S. 102. 
Die Wundererzählungen sind eng mit dem Stoff der Haupthandlung verknüpft, dem Verhalten eines Einzelnen und auch von Gruppen inner- oder außerhalb von klösterlichen, städtischen oder anderen Gemeinschaften. Wie oben festgestellt, sind sie immer an den Brüchen der Haupthandlung gesetzt. Sie variieren so das Thema der Haupthandlung und zeigen Verhaltensweisen von anderen Personen in ähnlichen Situationen auf. So führt Guibert die oben erwähnte Erzählung der Versuchung eines jungen Konversen nach der Erwähnung seiner eigenen Versuchung mit der Bemerkung ein, daß Dämonen mit Vorliebe junge Konversen angreifen ${ }^{18}$. Als Abschluß der Erzählung dient eine fast wörtliche Anlehnung an eine Stelle aus dem Lukas-Evangelium ${ }^{19}$.

$\mathrm{DaB}$ diese Erzählungen als Exkurse verstanden werden müssen, macht Guibert an mehreren Stellen deutlich, so zum Beispiel im ersten Buch: Die Wundergruppe, die am Schluß des Buches steht, wird mit der Bemerkung eingeleitet, daß einige Erzählungen aus Saint-Germer-de-Fly folgen würden. Dies zum Zeitpunkt, als Guibert dieses Kloster als gewählter Abt von Nogent verläßt ${ }^{20}$. Er schließt den Exkurs mit folgender Bemerkung ab: Haec de iis, quae in monasterio viderim aut audierim dixisse sufficiat ${ }^{21}$.

Im zweiten Buch fügt Guibert nach der Erwähnung seiner Rückkehr nach Saint-Germer-de-Fly nach der Übernahme des Abbatiats in Nogent ${ }^{22}$ einige Erzählungen aus diesem Kloster an, deren zwei von Dämonen handeln. Zum Thema "Erfahrungen mit Dämonen" fügt Guibert dann noch einmal zwei Exempla extra propositum, außerhalb des Berichtes, hinzu ${ }^{23}$ und schiebt, da er seine Rede nicht unterbrechen möchte, eine weitere Erzählung nach, die noch einmal das Thema "Kampf gegen Dämonen " variiert ${ }^{24}$. So auch im dritten Buch, wo Guibert erwähnt, daß er nicht alle Wunder der heiligen Maria von Laon auf der Reliquienreise nach England anführen wolle, sondern nur diejenigen, die zu Predigtzwecken geeignet seien ${ }^{25}$. Der Abschnitt wird mit der Bemerkung abgeschlossen, daß einige wenige Beispiele der Wunderkraft

18 Guibert DE Nogent, Autobiographie, I, 15, S. 118: Plurimis etiam auditarum rerum conjecturis experior adversus nuper conversos, seu eos qui ad hoc propositum semper aspirant, vehementius daemones acerbari.

19 Ibid. I, 15, S. 120: Si ergo gaudium est super uno peccatore converso in coelo quam super nonaginta novem qui non indigent poenitentia justis, procul dubio plenum fidei est hostes humani generis acerbissima invidentia de eorum, qui mutantur in melius, ereptione tristari. In Anlehnung an Luc. 15, 7: dico vobis quod ita gaudium erit in caelo super uno peccatore paenitentiam habente quam super nonaginta novem iustis qui non indigent paenitentia.

20 Zitat siehe oben, S. 164, Anm.9.

21 Guibert de Nogent, Autobiographie, I, 26, S. 208.

22 Diese zeitweilige Rückkehr nach Saint-Germer-de-Fly behandelt Guibert sehr diskret, siehe oben, S. 30, Anm. 153.

23 GuIBERT DE NOGENT, Autobiographie, II, 5, S. 258: Sunt enim quaedam daemonia solis ludibriis intenta, sunt et aliqua mente crudelia, et ad laedendum prona. Cujus verbi gratia extra propositum duo exempla proponimus.

24 Ibid. II, 6, S. 264: Conceptum sermonem tenere quis possit?

25 Ibid. III, 13, S. 388: Non enim odeporicum eorum scribimus, ipsi conscribant, nec facta viritim, sed quaeque praedicatoria decerpimus. 
Mariens, die sie auf der Reise nach England unter Beweis stellte, genügen würden ${ }^{26}$. Diese Reserve ist eine beliebte rhetorische Figur in Mirakelsammlungen, kündigt hier aber die Stellung der Wundererzählungen als Exempla $a^{27}$. Gerade diese Serie von Wundern lädt zu einer Überprüfung der Aussage Guiberts über die Auswahl der Erzählungen ein, da Hermann von Tournai die Wunder derselben Reliquienreise rund 30 Jahre später in einem Mirakelbuch festhält ${ }^{28}$. Während Guibert nach der Schilderung der gefahrenvollen Überfahrt nach England nur zwei Episoden berichtet, erwähnt Hermann deren 18, wovon ein großer Teil Heilungswunder sind. Da die Kleriker aus Laon mit großer Wahrscheinlichkeit Guibert von den Wundertaten berichteten oder auf der Reise schon Notizen hergestellt hatten, kann ein Auswahlverfahren Guiberts angenommen werden, das die gewöhnlichen Heilungswunder ausschlo $\beta^{29}$. Er berichtet nur zwei Episoden: ein Strafwunder an den Bewohnern eines Dorfes, die Kleriker und Reliquien nicht empfangen wollten, und die Geschichte eines Diebes, der Spenden, welche die Kleriker aus Laon gesammelt hatten, entwendete und sich anschließend im Wald erhängte $^{30}$. Allerdings dürfen nicht nur Wundererzählungen als Exkurse betrachtet werden, sondern ebenso die oben erwähnten Darstellungen von Konversionen von Adeligen oder Gründungen neuer Orden ${ }^{31}$.

\section{Der sogenannte »Wunderanhang « am Ende des dritten Buches}

Als »Wunderanhang « hat Gabriela Signori die letzten drei Kapitel des dritten Buches der Monodiae bezeichnet ${ }^{32}$. In welchem Zusammenhang der »Wunderanhang « zu den anderen Teilen der Schrift steht, ist nicht auf den ersten Blick ersichtlich. Diese Gruppe kann nicht eindeutig als Exkurs bezeichnet werden, da Guibert sein drittes Buch mit diesen Wundererzählungen abschließt. Auch ist der Erzähler Guibert zum Schluß dieser Gruppe wieder selbst im Text präsent. Die Wundererzählungen sind wie in den anderen Exkursen nach assoziativ-digressorischem Kompositionsprinzip aneinandergefügt ${ }^{33}$. Um dieses Kompositionsprinzip zu verdeutlichen, sollen die Geschichten, die am Ende des dritten Buches (Kap. 18-20) eingefügt sind, in ihrer Abfolge analysiert wer-

26 Ibid. III, 13, S. 392: Ex multis quae apud Anglos Virgo imperiosa peregit, haec nos excepisse sufficiat.

27 Sigal, Travail, S. 182. Siehe dazu auch oben, S. 48.

28 Hermann von Tournal, De miraculis sanctae Mariae Laudunensis, Buch II, Sp. 973-988; dazu Signori, Maria, S. 114-124; KAISER, Verbrechen und Strafe, S. 89-91.

29 Hermann von Tournai erklärt, von den Wundern auf mündlichem Wege erfahren zu haben. Signori, Maria, S. 105f. Zu Guiberts Unterscheidung von gewöhnlichen und ungewöhnlichen Wundern siehe oben, S. 47f.

$30 \mathrm{Zu}$ letzterer Geschichte siehe SIGNORI, Maria, S. 108.

31 Siehe oben, S. 163.

32 Signori, Maria, S. 107.

33 Moos, Geschichte, S. 351 und Anm. 692 beschreibt die Kompositionsprinzipien des Policraticus des Johann von Salisbury. Seine Analyse ist für die Einordnung von Guiberts Exkursen richtungsweisend. 
den. Auf den ersten Blick überrascht das ungeordnete Aufeinanderfolgen von Erzählungen, die ohne Zusammenhang nebeneinander gestellt scheinen. Diese sind in parataktischer Reihung aneinandergefügt, wie dies in mittelalterlichen literarischen und historiographischen Werken oft gepflegt wurde. Als Merkmale dieser Reihungen werden das Fehlen von kausaler Verknüpfung zwischen einzelnen Episoden und das Nebeneinanderstellen von scheinbar Unverbundenem genannt ${ }^{34}$. Peter von Moos geht nicht von einem übergreifenden Leitgedanken aus, der sich hinter der Auswahl der Episoden verbirgt, sondern spricht von einem Nebeneinanderfügen von Erzählungen, die nach Thema und Topos verwandt sind ${ }^{35}$. Daß diese Zusammenhänge schon dem ersten Herausgeber des gesamten Textes, Dom Luc D'Achéry, im 17. Jahrhundert aufgefallen waren, zeigt sich an den Kapiteleinteilungen, die er aufgrund der Abschnitte in der Handschrift Baluze 42 vornahm ${ }^{36}$. In der Edition D'Achéry fehlen im 19. Kapitel drei Episoden, die Geschichte aus Montecassino und zwei Geschichten aus Fleury ${ }^{37}$. Ob D'Achéry diese wegließ, weil sie ihm nicht in den Zusammenhang des Wunderanhangs zu passen schienen, wie dies Bourgin vermutet ${ }^{38}$, oder weil die für den Papst nicht sehr schmeichelhafte Geschichte als der apologetischen Stoßrichtung der Editoren nicht dienlich eingeschätzt wurde, wie dies Dolbeau vermutet ${ }^{39}$, muß hier offen gelassen werden.

Bei den Erzählungen des Kapitels 18 handelt es sich um Straf- oder Heilungswunder durch Maria und drei Heilige, den heiligen Nicasius, den heiligen Justus und den heiligen Marcellus. So thematisiert die erste Erzählung, ein kombiniertes Straf- und Erlösungswunder, die Verletzung eines Festtages. Die zweite und die dritte Episode handeln von Übergriffen auf Kirchengut, die vierte von der Beleidigung einer Kirche, gefolgt von einem Versuch, Reliquien

34 Diese Reihungen von Erzählungen wurden in Übertragung des grammatischen Begriffs »Parataxe« von Peter von Moos in: ibid. S. 363 und Anm. 722, unter Bezug auf PARTNER, Serious Entertainments, S. 195-211 als parataktisch bezeichnet. AUERBACH, Mimesis, S. 72 f. u. passim legt dar, daß der parataktische Erzählstil, dessen Merkmal die Verbindung von Satzgliedern auf gleicher Ebene ist (so durch et ... et), im Gegensatz zum klassischen, von hypotaktischen Verbindungen von Satzgliedern geprägten Stil steht. In Anlehnung an den biblischen Stil ist er für mittelalterliche Literatur typisch.

35 Moos, Geschichte, S. 363 u. Anm. 722.

36 Diese Handschrift ist ebenfalls nur eine Kopie aus dem 17. Jahrhundert. Dazu siehe Guibert/Ed. Bourgin, S. XL. Zu dieser Edition: Fohlen, D'Achéry, S. S2-56, $135 \mathrm{f}$.

37 GuiberT DE Nogent, Autobiographie, III, 19, S. 456-458. Auch im zweiten Buch hatte D'Achéry eine Episode aus dem 5. Kapitel nicht in seine Edition aufgenommen. (Ibid. II, 5, S. 252-254). Zur Montecassino-Geschichte siehe auch oben, S. 117f.

38 Guibert/Ed. Bourgin, S. 225, Anm. 3. Er argumentiert aufgrund des Satzes, mit dem der Exkurs abgeschlossen wird: Sed stilum jam ad laetiora vertamus. Bourgin vermutet, daß sich dieser Satz nicht auf die unmittelbar folgende Monte-Cassino-Erzählung bezieht, sondern vielmehr auf die Wunder von Heiligen des 20 . Kapitels. In der Edition D'Achéry sind die drei Simonie-Geschichten nicht eingefügt. Mangels Handschriften können jedoch nur Vermutungen geäußert werden, wann diese in den Text eingefügt wurden. Siehe GuiBERT DE Nogent, Autobiographie, III, 19, S. 456, Anm. 2.

39 Dolbeau, Manuscrits, S. 160. 
zu schänden ${ }^{40}$ und einem Mordversuch an einem Priester. Betroffen von den wunderbaren Ereignissen sind ein einfaches Mädchen, zwei Ritter, ein Vogt, ein Vasall und ein Priester. Alle diese Erzählungen thematisieren Übergriffe auf die kirchliche Autorität. Diese Übergriffe auf die kirchliche Sphäre werden sanktioniert. Im Fall des Mädchens kann die Strafe durch Gebet wieder rückgängig gemacht werden, im Fall des Übergriffs auf den Priester verhindert ein Wunder das Gelingen des Mordversuchs.

Tab. 2: Straf- und Heilungswunder durch Maria und Heilige

\begin{tabular}{lllll}
\hline $\begin{array}{l}\text { Bibliogra- } \\
\text { phische } \\
\text { Referenz }\end{array}$ & $\begin{array}{l}\text { Wunder/ } \\
\text { Legende }\end{array}$ & $\begin{array}{l}\text { Wundertäter/in, } \\
\text { Intervenient }\end{array}$ & $\begin{array}{l}\text { Art der } \\
\text { Erzählung }\end{array}$ & Betroffene/r \\
\hline $\begin{array}{l}\text { III, 18, S. 434 } \\
\text { III, 18, S. 436 }\end{array}$ & $\begin{array}{l}\text { Sonntagsarbeit } \\
\text { Beten nach obigem } \\
\text { Strafwunder }\end{array}$ & $\begin{array}{l}\text { Nicasius } \\
\text { Maria } \\
\text { III, 18, S. 438 }\end{array}$ & $\begin{array}{l}\text { Strafwunder } \\
\text { Erlösungs- } \\
\text { wunder }\end{array}$ & $\begin{array}{l}\text { armes Mädchen } \\
\text { armes Mädchen }\end{array}$ \\
III, 18, S. 438 & $\begin{array}{l}\text { Entwendung der } \\
\text { Fischrechte }\end{array}$ & $\begin{array}{l}\text { Maria (Patronin } \\
\text { der geschädigten } \\
\text { Abtei) } \\
\text { Maria (Patronin } \\
\text { der geschädigten } \\
\text { Abtei) }\end{array}$ & Strafwunder & Ritter \\
III, 18, S. 440 & $\begin{array}{l}\text { Vogt bedrängt } \\
\text { Kirche }\end{array}$ & $\begin{array}{l}\text { Maria, Cornelius, } \\
\text { Cyprian }\end{array}$ & Strafwunder & $\begin{array}{l}\text { Röniglicher } \\
\text { Reliquienschändung }\end{array}$ \\
Justus & Strafwunder & $\begin{array}{l}\text { unwürdiger } \\
\text { Vasall }\end{array}$ \\
III, 18, S. 440, S. 440 & $\begin{array}{l}\text { Vergiftungsversuch } \\
\text { an Priester }\end{array}$ & Marcellus & $\begin{array}{l}\text { Heilungs- } \\
\text { wunder }\end{array}$ & Priester \\
\hline
\end{tabular}

Im Kapitel 19 läßt sich als Gemeinsamkeit einer ersten Gruppe von sechs Episoden ausmachen, daß sie alle Übergriffe des Teufels thematisieren. Die Handlung der ersten vier Erzählungen steht mit dem Tod in Zusammenhang, der in Beziehung zu sündigem Leben gestellt wird. Die zwei ersten Erzählungen sind Wiedergängerlegenden, weitere zwei handeln von Wucherern, die wegen ihrer Geldgier vom Teufel geholt werden. Die letzten zwei Erzählungen dieser Gruppe berichten von Eingriffen des Teufels, werden aber nicht mit Tod oder Sünde in Beziehung gesetzt. In dieser Gruppe sind ein junger

40 In Saint-Just prozessieren die Kleriker während eines Aufstandes mit den Reliquien des heiligen Justus. Ein Mann versucht mit dem Schwert die Reliquien zu verletzen. Der heilige Justus wurde in Simonovicus (Saint-Just-en-Chaussée) ermordet. Der Körper des Märtyrers wurde in einer Grotte beerdigt, der Kopf nach Auxerre gebracht. Die Reliquien wurden dann, sehr wahrscheinlich während den Invasionen der Normannen, in die Kathedrale SaintPierre in Beauvais transferiert. 1107 setzte der Bischof Gottfried von Beauvais Kleriker in Saint-Just ein. GC, Bd. 9, Sp. 719 und 849. Die Kleriker, welche gemäß Guiberts Bericht mit den Reliquien prozessierten, könnten Kleriker aus Beauvais gewesen sein, die in ihre villa fuhren, um dort den Aufstand niederzuschlagen. Guibert kann die Geschichte auf mündlichem Wege in Beauvais erfahren haben. Für die Auskünfte danke ich Floriane Guignet. 
Mann, ein Mönch, Wucherer, Adelige und ein Bauer von den Eingriffen betroffen. Sie wird abgeschlossen mit der Bemerkung, daß weitere Übergriffe des Teufels gegen Frauen angeführt werden könnten, dies aber unterlassen werde ${ }^{41}$. Darauf folgen die oben erwähnten drei Episoden, die in D'Achérys Edition fehlen. Die drei Episoden weisen wiederum einige Gemeinsamkeiten auf: Sie betreffen allesamt Probleme bei der Besetzung von kirchlichen Ämtern, im Falle des Desiderius von Montecassino des Papstamtes, in den zwei anderen Fällen des Abbatiats von Fleury. Einzig die zweite der Episoden aus Fleury, die Veranus, einen Verwandten Guiberts betrifft, weist keine wunderbaren Züge auf ${ }^{42}$. Immer aber spielen die Vorfälle in Klöstern des heiligen

Tab. 3: Eingriffe des Teufels und Vorfälle in Benedikt-Klöstern

\begin{tabular}{|c|c|c|c|c|}
\hline $\begin{array}{l}\text { Bibliogra- } \\
\text { phische } \\
\text { Referenz }\end{array}$ & $\begin{array}{l}\text { Wunder/ } \\
\text { Legende }\end{array}$ & $\begin{array}{l}\text { Wundertäter/in, } \\
\text { Intervenient/in }\end{array}$ & $\begin{array}{l}\text { Art der } \\
\text { Erzählung }\end{array}$ & Betroffene/r \\
\hline III, 19, S. 442 & $\begin{array}{l}\text { Jakobspilger/ } \\
\text { Santiagopilger- } \\
\text { legende }\end{array}$ & Maria & $\begin{array}{l}\text { Versuchung } \\
\text { des Teufels, } \\
\text { Wiedergänger }\end{array}$ & $\begin{array}{l}\text { junger Mann, der } \\
\text { aus Reue wegen } \\
\text { Ehebruchs nach } \\
\text { Santiago pilgert }\end{array}$ \\
\hline III, 19, S. 448 & $\begin{array}{l}\text { Verletzung der } \\
\text { stabilitas loci }\end{array}$ & $\begin{array}{l}\text { Gott durch } \\
\text { Richter Richard }\end{array}$ & $\begin{array}{l}\text { Teufel will Seele } \\
\text { entreißen } \\
\text { Wiedergänger- } \\
\text { legende }\end{array}$ & $\begin{array}{l}\text { Laie, ins Kloster } \\
\text { eingetreten }\end{array}$ \\
\hline III, 19, S. 450 & $\begin{array}{l}\text { Wucher } \\
\text { in Laon }\end{array}$ & Teufel & $\begin{array}{l}\text { Erläuterung der } \\
\text { Todesart schlechter } \\
\text { Menschen }\end{array}$ & Wucherer \\
\hline III, 19 , S. 450 & $\begin{array}{l}\text { Teufel schenkt } \\
\text { Stier }\end{array}$ & Teufel & $\begin{array}{l}\text { Erläuterung der } \\
\text { Todesart schlechter } \\
\text { Menschen }\end{array}$ & geiziger Mann \\
\hline III, 19, S. 452 & Dachsenjagd & Teufel & Teufelsgeschichte & $\begin{array}{l}\text { Adelige aus dem } \\
\text { Vexin }\end{array}$ \\
\hline III, 19, S. 454 & $\begin{array}{l}\text { Gefesselter } \\
\text { Bauer }\end{array}$ & Teufel & Teufelsgeschichte & Bauer \\
\hline III, 19, S. 456 & $\begin{array}{l}\text { Simonie des } \\
\text { Desiderius }\end{array}$ & Benedikt & Strafwunder & $\begin{array}{l}\text { Desiderius von } \\
\text { Montecassino }^{43}\end{array}$ \\
\hline III, 19, S. 458 & $\begin{array}{l}\text { Verschwinden } \\
\text { auf der Latrine }\end{array}$ & & schlechter Tod & $\begin{array}{l}\text { Mönch aus } \\
\text { Fleury }\end{array}$ \\
\hline III, 19, S. 458 & $\begin{array}{l}\text { Ausschluß aus } \\
\text { Kloster/Abtwürd }\end{array}$ & & & $\begin{array}{l}\text { Veranus, Ver- } \\
\text { wandter Guiberts }\end{array}$ \\
\hline
\end{tabular}

41 Guibert de Nogent, Autobiographie, III, 19, S. 456. Die Wendung sed stilum jam ad laetiora vertamus ist ein typischer AbschluB eines solchen Exkurses. Siehe dazu oben, S. 169, Anm. 38 .

42 GuiberT DE Nogent, Autobiographie, III, 19, S. 458: Vidi et Veranum, virum nobilem, cognatum meum, cum etiam vis regia adniteretur, tantis injuriis ac vilipensioni addictum, ut ab abbatia ultro exponeretur.

${ }^{43}$ Desiderius von Montecassino ist als Victor III. von 1086-87 Nachfolger von Gregor VII. Siehe dazu oben, S. 117. 
Benedikt, der in der ersten Erzählung auch interveniert. Das Thema der Sünde wird diesmal für die kirchlichen Funktionsträger variiert. Abgeschlossen wird die Gruppe durch den Hinweis, daß wegen Abweichens von der Regel mehrere Mönche aus Fleury eines unwürdigen Todes gestorben seien.

Die zehn Erzählungen des 20. Kapitels betreffen Straf-, Heilungs- und Rettungswunder durch Heilige oder deren Reliquien. Dabei wirken sowohl Heilige aus England als auch Reliquien, die in nächster Umgebung Guiberts in der Region von Beauvais verehrt werden. So betrifft das drittletzte Wunder, eine Heilung am Altar des heiligen Leodegar, Guibert als kleinen Jungen selber. Am Schluß des Wunderanhangs stehen zwei Marienwunder, die sich in SaintDenis abspielen. Die Betroffenen der Wunder stammen wieder aus verschiedensten gesellschaftlichen Schichten: zweimal ein Abt, ein Mönch, ein Adeliger, Diebe, Passanten und Guibert selbst. Zudem kommt ein Reh in den Genuß eines Wunders. Diese Gruppe von Wundererzählungen könnte die hagiographischste der drei Kapitel genannt werden: Die Erzählungen dienen zum Beweis der Stärke der intervenierenden Heiligen. Maria als wichtigste Heilige für Guibert und Patronin seiner Abtei in Nogent bildet den Abschluß der Gruppe von Wundern.

Tab. 4: Straf-, Heilungs- und Rettungswunder durch Heilige oder deren Reliquien

\begin{tabular}{|c|c|c|c|c|}
\hline $\begin{array}{l}\text { Bibliogra- } \\
\text { phische } \\
\text { Referenz } \\
\end{array}$ & $\begin{array}{l}\text { Wunder/ } \\
\text { Legende }\end{array}$ & $\begin{array}{l}\text { Wundertäter/in, } \\
\text { Intervenient/in }\end{array}$ & $\begin{array}{l}\text { Art der } \\
\text { Erzählung }\end{array}$ & Betroffene/r \\
\hline III, 20 , S. 460 & $\begin{array}{l}\text { Wunderbarer Kör- } \\
\text { per von König Ed- } \\
\text { mund }\end{array}$ & König Edmund & Strafwunder & $\mathrm{Abt}$ \\
\hline III, 20, S. 460 & lahmendes Reh & König Edmund & Heilung & lahmendes Reh \\
\hline III, 20, S. 462 & wunde Hände & Swithun & Heilung & Mönch \\
\hline III, 20, S. 462 & Feuerprobe & Arnulf & Beweiswunder & $\begin{array}{l}\text { Einwohner sei- } \\
\text { ner Heimatstad }\end{array}$ \\
\hline III, 20, S. 462 & $\begin{array}{l}\text { Krankheit geht } \\
\text { zuerst im Körper } \\
\text { herum, bevor sie } \\
\text { geheilt wird }\end{array}$ & Arnulf & Heilung & $\begin{array}{l}\text { Cousin Gui- } \\
\text { berts, Adeliger } \\
\text { der Stadt }\end{array}$ \\
\hline III, 20, S. 464 & $\begin{array}{l}\text { Diebstahl des } \\
\text { andern Arms des } \\
\text { hl. Arnulf }\end{array}$ & Arnulf & Strafwunder & Diebe \\
\hline III, 20, S. 464 & $\begin{array}{l}\text { Goldfassung des } \\
\text { Arms des hl. Arnulf }\end{array}$ & Arnulf & $\begin{array}{l}\text { Wille des Heili- } \\
\text { gen }\end{array}$ & \\
\hline III, 20, S. 464 & $\begin{array}{l}\text { Fieberheilung des } \\
\text { kleinen Guibert }\end{array}$ & Leodegar & Heilung & $\begin{array}{l}\text { Guibert als } \\
\text { kleiner Junge }\end{array}$ \\
\hline III, 20, S. 466 & $\begin{array}{l}\text { Schlußwunder: } \\
\text { Turm in Saint- } \\
\text { Denis, Teil } 1\end{array}$ & Maria & $\begin{array}{l}\text { Vision und Ret- } \\
\text { tung durch Ma- } \\
\text { ria }\end{array}$ & $\begin{array}{l}\text { Abt von Saint- } \\
\text { Denis }\end{array}$ \\
\hline III, 20, S. 466 & $\begin{array}{l}\text { Schlußwunder: } \\
\text { Turm in Saint- } \\
\text { Denis, Teil } 2\end{array}$ & $\begin{array}{l}\text { Maria und } \\
\text { Dionysius }\end{array}$ & $\begin{array}{l}\text { Rettungswun- } \\
\text { der }\end{array}$ & Passant \\
\hline
\end{tabular}


Der Wunderanhang in den Kapiteln 18-20 steht mit der Haupthandlung des dritten Buches, der Tragödie der Leute von Laon, insofern in Zusammenhang, als er die Botschaft der Tragödie der Bewohner von Laon variiert ${ }^{44}$. Guibert drückt damit aus, daß die Sündhaftigkeit der Bischöfe von Laon die ganze städtische Gesellschaft ins Verderben stürzt. Mit den Wundererzählungen verdeutlicht er, daß sündhaftes Verhalten in allen sozialen Schichten in der Diözese, aber auch in der Region vorherrscht und zum Verderben beiträgt. So werden in den Kapiteln 18 und 19 ebenfalls sündige Verhaltensweisen von Personen aus allen gesellschaftlichen Schichten thematisiert. Die letzte Gruppe von Erzählungen zeigt hingegen einen hoffnungsfrohen Gegenentwurf zu diesen sündhaften Verhaltensweisen: Die Stärke der Heiligen, die heilen und retten, so wie einer von ihnen das Kind Guibert geheilt hatte.

Guibert schreibt die Monodiae entlang den Stationen seines eigenen Lebens. Die Exkurse weisen darauf hin, daß er sein Leben als Beispiel für sündige Verhaltensweisen darstellt. In den Exkursen variiert er Verhaltensweisen anderer in ähnlichen Situationen ${ }^{45}$. Auf gleiche Weise geht Guibert auch in den anderen Teilen des Textes vor, beispielsweise bei der Darstellung der Tragödie der Einwohner von Laon. Durch die Negativ-Beispiele der Verhaltensweisen der Bischöfe von Laon bringt er sein Ideal kirchlicher Führung zum Ausdruck ${ }^{46}$.

Deutungen von Wundererzählungen: Lektionen für Mönche, Kleriker und Laien

Im ersten Kapitel dieser Arbeit steht die Deutung eines Ereignisses als Wunder im Zentrum. Nachdem ein Ereignis von Guibert oder von seiner Umgebung als Zeichen Gottes, als Wunder, gedeutet wurde, mußte der Sinn oder die Bedeutung des Zeichens erschlossen werden. Diese Deutungsarbeit konnte entweder durch die Gemeinschaft, innerhalb derjenigen das Zeichen gedeutet wurde, oder aber in einem Text, innerhalb desselben das Zeichen Bedeutung tragen sollte, geleistet werden. Die Deutungsarbeit ist demnach zweischichtig. In einem ersten Schritt muß ein Ereignis als Zeichen gedeutet werden, in einem zweiten Schritt muß das Zeichen in seiner Bedeutung für eine gesellschaftliche Gruppe interpretiert werden ${ }^{47}$.

Guibert legt seine Deutungen der in den Monodiae eingefügten Wundererzählungen oft in einleitenden oder abschließenden Bemerkungen offen. Diese

\footnotetext{
44 Der Übergang der Tragödie der Leute von Laon zu den Wundererzählungen der letzten drei Kapitel ist fließend. Es werden die Verhältnisse in der Stadt und Diözese Laon geschildert, aber auch Johannes von Soissons als nicht zu rettender Sünder beschrieben und Häresien in der Region dargestellt.

45 Dies stützt die Einschätzung von Jay Rubenstein, daß Guibert die Monodiae verfaßt, um seine Leser zu Reflexion über sich selbst und über die Funktionsweise des Geistes anzuregen, RuBENSTEIN, Guibert of Nogent, S. 73.

46 Lemmers, Crisis of Episcopal Authority, S. 50.

47 Zur Deutung von Ereignissen als Wunder siehe oben, Kap. 2.1.
} 
können auch in Zusammenhang mit Schriftzitaten stehen. So fügt Guibert beispielsweise im zweiten Buch die Erzählung der drei Fieber ein, die einem Wächter des Klosters Saint-Médard de Soissons in Form von drei Frauen erscheinen, dann aber einen reichen Kleriker angreifen. Dieser beginnt sogleich unter hohem Fieber zu leiden. Guibert kommentiert die Episode mit der Bemerkung, daß solche Krankheiten oft von Dämonen verursacht werden ${ }^{48}$. Diese Schlußfolgerung untermauert er mit Bezügen auf drei verschiedene Stellen aus den biblischen Schriften, auf Lukas, 13, 11, Markus 9, 17-29 und Ijob 1-249. Wieso der reiche Kleriker angegriffen wird, macht Guibert nicht explizit.

Zuweilen referiert Guibert verschiedene Versionen von Deutungen. So in einer Passage aus den Monodiae. Nachdem der Bischof Gaudry von Laon den Mord an Gérard von Quierzy, Kastellan des Klosters Saint-Jean-de-Laon, vorbereitet hat, begibt er sich auf eine Reise nach Rom. Am selben Tag soll sich ohne äußere Einwirkung ein Adler aus dem Goldschmuck des Reliquienkastens gelöst haben und heftig auf dem Boden aufgeschlagen sein. Guibert setzt der einen Deutung, daß dies ein Vorzeichen des Todes des Bischofs sei, eine weitere entgegen, ohne jedoch die erstere zu verwerfen. Er schlägt vor, das Geschehen als Vorzeichen des Zerfalls der Königsstadt zu deuten, da sie seither kein König mehr betreten habe ${ }^{50}$. Die Urheber der ersten Deutung beschreibt Guibert nur undeutlich mit quidam. Seine zweite Deutung unterstreicht auf der Ebene des Textes die Gesamtaussage des dritten Buches, die Tragödie der Bewohner der Bischofsstadt Laon ${ }^{51}$.

Die Funktion der Wundererzählung ais Exemplum ist eine didaktische. In seinen Kommentierungen verdeutlicht Guibert die Lehre, die er durch die Erzählung erteilen will. Guibert scheint seine Lehren sowohl einem monastischen als auch einem weltlichen Empfängerkreis erteilen zu wollen.

\section{Wundererzählungen im Kloster: Das Verhalten Einzelner in der} monastischen Gemeinschaft

Ein großer Teil der Wundererzählungen stammt aus dem monastischen Milieu, vor allem diejenigen, die in den ersten zwei Büchern erzählt werden. $\mathrm{Zu}$ großen Teilen müssen auch die Dämonenerzählungen diesem Milieu zugeordnet werden. Diese thematisieren in vielen Fällen das Verhalten Einzelner in der monastischen Gemeinschaft. Guiberts Kommentare beziehen sich auf Verhaltensweisen, die jeder Mönch anstreben sollte. So thematisiert eine Wiedergängergeschichte das Gebot der stabilitas loci. Obwohl die Erzählung we-

48 Guibert de Nogent, Autobiographie, II, 6, S. 262.

49 In Luc. 13, 11 befreit Jesus eine Frau von einem Dämon, der ihren Rücken verkrümmt hatte. In Marc. 9, 17-29 heilt Jesus einen Besessenen, in Iob 1-2 wird Ijob durch den Satan versucht. Dieses Vorgehen wird auch in hagiographischen Texten angewendet, siehe bspw. in der Vita S. Godefridi, AASS Nov. III, S. 919.

50 GuiberT de Nogent, Autobiographie, III, 13, S. 392-394.

51 Vgl. dazu KaISER, Guibert de Nogent. 
gen ihres Themas - dem Schicksal eines Wiedergängers - an die vorhergehende angefügt ist, betont Guibert im Kommentar der Erzählung die Lehre, die ein Mönch aus der Erzählung ziehen soll52. Guibert scheint das Problem der stabilitas loci aus eigener Erfahrung zu kennen, wie dies die Andeutungen im zweiten Buch deutlich machen ${ }^{53}$.

Das Thema von Buße und Reue wird zweimal abgehandelt, im ersten und im dritten Buch. In beiden Fällen ist kein expliziter Kommentar notwendig, um die Botschaft der Erzählung zu verdeutlichen. Die erste Episode spielt im Kloster Saint-Germer-de-Fly und ist ein Bestandteil einer mehrteiligen Erzählung über die drei Blitze, die im Kloster einschlagen ${ }^{54}$. Nach dem ersten Blitzschlag hat sich das Gesicht einer Marienstatue verzogen. Der Blitzschlag, der einige Mönche getötet, einige verletzt hat, wird so in Zusammenhang gesetzt mit der Veränderung der Mimik der Marienstatue. Erst die Gewissenserforschung und das Bewußtwerden der Sünden bewirken eine Rückkehr zum vorherigen, lieblichen Zustand des Gesichts der Statue.

Auch die Geschichte des Desiderius von Montecassino, der nach seiner kurzen Zeit als Papst in seinem Kloster nicht mehr das Amt des Abtes einnehmen kann, sondern als Pförtner dienen muß, ist für das Thema Buße und Reue aussagekräftig. Nach einem Jahr bescheidener Amtsausübung wird er von neuem zum Abt gewählt ${ }^{55}$. Die nachfolgende Erzählung verdeutlicht den gegenteiligen Fall: Ein Mönch aus Fleury versucht mit Hilfe von Geld des französischen Königs dem Abt Abbo die Abtei zu entreißen. Als Abbo ihn sucht, um ihn zur Umkehr und Reue zu bewegen, findet er ihn zufälligerweise. Der Mönch ist nicht zur Umkehr bereit, flieht und verschwindet auf der Latrine auf unerklärliche Weise ${ }^{56}$. Diese Geschichten, die sich sowohl im ersten als auch im dritten Buch der Monodiae finden, variieren das Überthema des Werkes: Gewissenserforschung, Sünde und Umkehr.

Weitere Erzählungen thematisieren zwei sündige Verhalten, wovon Guibert immer wieder spricht: das Thema des Mißbrauchs von Geld und das Thema des Abweichens vom rechten Glauben. In Bezug auf das erste Thema werden mehrere Erzählungen von Mönchen eingefügt, die Geld entwendeten und darauf tödlich krank wurden. So ein Mönch aus Fly, der von Spenden der Gläubigen für den Bau einer Straße einen Teil für sich behielt, oder ein anderer, der zwei Dukaten, die er von einer adeligen Dame erhalten hatte, unter seiner Achsel versteckte ${ }^{57}$. In den Kommentaren betont Guibert die Schwere

52 Guibert De Nogent, Autobiographie, III, 19, S. 448-450. Siehe oben, Tab. 3. Zur stabilitas loci siehe Fichtenau, Lebensordnungen, S. $347 \mathrm{f}$.; RÜTHER, Art. »stabilitas loci«.

53 Siehe dazu oben, S. 30, Anm. 153.

54 Guibert DE Nogent, Autobiographie, I, 23, S. 182, dazu oben, S. 143.

55 Ibid., III, 19, S. 456-458. Siehe oben, S. 171, Anm. 43.

56 Ibid., III, 19, S. 458. Siehe oben, Tab. 3.

57 Ibid., I, 21, S. 172 und I, 22, S. 176. Eine Kurzbeschreibung und Deutung dieser Erzählungen bietet KaISER, Geld, S. 297. 
des Lasters der philargyria, der Geldgier, das er bei Mönchen als besonders schwerwiegend charakterisiert ${ }^{58}$.

Das zweite Thema, das Abweichen vom rechten Glauben, wird durch eine Erzählung einer versuchten Hexerei verdeutlicht und steht in einer Gruppe von Erzählungen, die durch das Thema »Anfechtung durch Dämonen« verbunden sind. Ein Mönch, der sich nur mit einem Begleiter in einer cella eines großen Klosters aufhält, lernt mit Hilfe eines Juden zu hexen. Zudem pflegt er Besuch von einer Frau zu empfangen. Als der Begleiter die beiden einmal unverhofft überrascht, wendet der Mönch seine Zauberkünste an und verwandelt die Frau in einen Hund. Als er darauf krank wird, gesteht er die Ereignisse. Auf Rat des Anselm von Bec/Canterbury wird ihm darauf das Priesteramt entzogen. Trotzdem will er Bischof werden, stirbt aber bald, ohne die Erlaubnis wiedererlangt zu haben, die priesterlichen Funktionen von neuem auszuüben $^{59}$. Dieser Erzählung wird eine weitere zum Thema "Hexerei« angefügt, die jedoch einen Kleriker betrifft, der in Fly als Schreiber tätig war ${ }^{60}$.

Krankheit und ein schlechter oder plötzlicher Tod wurden in hagiographischen Texten oft als Sieg von Dämonen über die betroffenen Personen begriffen, konnten daher nicht nur eine körperliche Angelegenheit sein ${ }^{61}$. Dies zeigt sich auch in Guiberts Schriften. Seine Kommentare machen deutlich, daß Krankheit oder Tod von Mitgliedern der monastischen Gemeinschaft erklärt werden mußten und mit Verhaltensweisen und Charakterzügen der Betroffenen vor ihrem Tode in Beziehung gesetzt wurden ${ }^{62}$. So auch in der oben angesprochenen Geschichte der drei Blitze, die im Kloster Saint-Germer-de-Fly Todesopfer forderten ${ }^{63}$. Guibert erklärt den Tod von zwei Mönchen als Strafe für ihr sündhaftes Verhalten, denjenigen des dritten als direkten Einstieg ins Paradies. Um diese Auslegung zu untermauern, führt Guibert eine Vision an, die ein Ungenannter in bezug auf das weitere Schicksal der drei Mönche gehabt habe.

Immer wieder betont Guibert in seinen Erzählungen den Stellenwert der Beichte vor dem Tod. Dies zeigen die zwei oben erwähnten Erzählungen von geizigen Mönchen. Während der erste der geizigen Mönche seine Tat noch vor dem Tod gestehen und so eines relativ ruhigen Todes sterben konnte, litt der zweite, der sein Geld heimlich unter der Achsel versteckt hat, unter einer entwürdigenden Darmkrankheit und starb ohne Beichte oder Krankensalbung ${ }^{64}$. Als die Gemeinschaft das Geld entdeckte, beerdigte sie den Leich-

58 Zur veränderten Stellung dieses Lasters ab dem 11. Jahrhundert siehe ibid. S.297, Anm. 39.

59 Guibert de Nogent, Autobiographie, I, 26, S. 200-206.

60 Ibid. I, 26, S. 206-208.

61 Vauchez, Miracle, S. 40.

62 Guibert de Nogent, Autobiographie, III, 19, S. 450: Quoniam de qualitatibus morientium loqui aliquotiens utile est [...].

63 Siehe oben, S. 175, Anm. 54.

64 Zitate siehe oben, S. 175, Anm. 57. 
nam außerhalb eines Friedhofs ohne jegliches Gebet. Deutlich wird so vor Augen geführt, welche Erleichterungen Beichte und Reue geständigen Sündern bringen können.

Wundererzählungen in der Welt: Sanktionen unchristlichen Verhaltens

Eine große Gruppe der Wundererzählungen aus dem weltlichen Bereich betrifft Sanktionen von Verletzungen der kirchlichen Autorität. Dies vor allem in der Gruppe von Erzählungen, die in Kapitel 18 zusammengefaßt sind (Tab. 2). Sie warnen vor der Verletzung der Festtagsruhe, vor der Entwendung von Kirchengut, dem mangelnden Respekt vor Reliquien und dem Priester als Person im Dienst der Kirche. So in der Erzählung, die in Saint-Just spielt. Die Reliquien wurden von den Klerikern während eines Aufstandes als Autorität eingesetzt, um Ruhe und Ordnung wiederherzustellen. Eine Verletzung des Reliquienschreins spottete aber der Kleriker als Verwalter der friedenstiftenden Autoritä̈ ${ }^{65}$. Der ausdrücklichste Kommentar Guiberts in dieser Gruppe von Erzählungen warnt vor Verletzungen der Autorität seiner eigenen Kirche von Nogent und kann daher als Selbstschutz aufgefaßt werden ${ }^{66}$.

Der zweite Themenbereich, die Durchsetzung des rechten Glaubens und Kults, steht mit der Durchsetzung der kirchlichen Autorität in engem Zusammenhang. Hier steht die Erzählung des Todes des Grafen Johannes von Soissons im Zentrum. Dessen Tod wird von Guibert als Strafe Mariens für seine blasphemischen Handlungen kommentiert. So findet seine Seele einen elenden Tod, indem die Dämonen seine Seele der heiligen Maria entwinden ${ }^{67}$. Dies aber auch im Falle eines Dieners, der den Teufel anruft, um über einen Fluß gesetzt zu werden. Dämonen als Gehilfen des Teufels packen ihn und setzen ihn in Italien wieder ab, wo ihn sein Herr wiederfindet. Dieses Erlebnis sei dem Diener eine Lektion gewesen, die er auch weitergegeben habe: Dämonen sollten nicht angerufen werden ${ }^{68}$. Edmond-René Labande macht in einer Fußnote auf den ironischen Unterton aufmerksam, den Guibert bei dieser Geschichte angeschlagen habe ${ }^{69}$. Als Lehrstück für einfache Leute scheint Guibert die Lektion aber durchaus als geeignet empfunden zu haben.

Der mißbräuchliche Umgang mit Geld bietet auch im weltlichen Bereich Stoff für Lehrstücke. Wucher und Geldgier sind auf ähnliche Weise Anlaß für

65 Siehe oben, S. 170, Anm. 40.

66 Guibert De Nogent, Autobiographie, III, 18, S. 438-440: Hoc unum didici, quod nemo isti ecclesiae infensus fuit, qui non ad evidens detrimentum venerit, si perseverare delegerit. Dies steht in Zusammenhang mit der von Rubenstein, Guibert of Nogent, S. 103 beobachteten Situation: Guibert ist als Abt eines weltlichen Eigenklosters den Herren von Coucy ausgeliefert und daher viel mehr als in Saint-Germer-de-Fly als bischöflichem Kloster der Willkür dieser weltlichen Herren ausgesetzt. Maria bietet, in Abwesenheit irdischer schützender Kräfte, den einzigen Schutz des klösterlichen Besitzes.

67 GuiberT de Nogent, Autobiographie, III, 16, S. 426-428.

68 Ibid. II, 6, S. 260-262.

69 Siehe zum Ironie-Begriff unten. S. 183, Anm. 98. 
schlechte Todesarten oder ein Ende bei den Dämonen ${ }^{70}$. Guibert stellt auch für den weltlichen Bereich Lehrstücke zusammen, die vor Angriffen von Dämonen warnen.

\section{Wundererzählungen und Predigt}

Die didaktische Absicht von Guiberts Werk wird aufgrund der Kommentare zu den Wundererzählungen deutlich. Der Diener, der von Dämonen auf unsanfte Weise transportiert worden ist, hat aus der Geschichte gelernt und gibt das Gelernte weiter ${ }^{71}$. Guibert erzählt, aus der Geschichte des Adeligen, der von der Jungfrau Maria geohrfeigt wurde, selbst seine Lehren gezogen zu haben $^{72}$. Die Geschichte des Mönches Otmund behandelt Guibert als beispielhaftes Lehrstück, das zum gemeinsamen Nachdenken über das Verhältnis von Dämonen und Menschen anregen soll ${ }^{73}$.

Es stellt sich nun die Frage, an welches Publikum sich diese Schrift wendet. Die Erzählungen aus dem monastischen Milieu richten sich an ein monastisches Publikum, das aus dem Gehörten seine Lehren ziehen kann, in erbaulicher Lektüre oder anläßlich von Predigten innerhalb der klösterlichen Gemeinschaft ${ }^{74}$. Die vielen Beispiele, die das Verhalten von Angehörigen aller Gesellschaftsschichten thematisieren, weisen aber darauf hin, daß Guibert auch Lehrstücke für Menschen jenseits der Klostermauern liefern will ${ }^{75}$. An zwei Stellen verdichtet sich dieser Verdacht. So nach der ausführlichen Darstellung des Wunders vom Mädchen mit dem Faden in der Zunge. Guibert nennt als parallele Quelle ein ähnliches Wunder, das Radbod, Bischof von Noyon, schriftlich festgehalten habe. Er weist dabei auf eine Predigt des Bischofs hin, die vielfach in Marienmirakelsammlungen überliefert ist ${ }^{76}$. Dann aber auch bei der Auswahl von Marienwundern, die sich auf der Reliquienreise ereignet haben. Guibert gibt an, diese Auswahl zu Predigtzwecken so getroffen zu haben ${ }^{77}$.

\section{Die Präsenz der Heiligen}

Guibert behandelt den Umgang mit Heiligen und Reliquien sowohl durch die inhaltliche Auswahl von Erzählungen als auch auf der Ebene der Kommenta-

70 Guibert de Nogent, Autobiographie, III, 19, S. 450-452.

71 Ibid. II, 6, S. 260-262: Ex his ergo quae passus est didicit et docuit Deum, non daemones pro negotiis invocandos.

72 Ibid. III, 18, S. 438: Hoc unum didici [...].

73 Ibid. I, 25, S. 198: [...] sed quod omnes mecum pensare commoneam [...].

74 Fuchs, Wundererzähler, S. 332.

$75 \mathrm{Zu}$ vermuten ist, daß nicht von einer allzu strikten Trennung von klösterlicher und laikaler Gemeinschaft auszugehen ist. So ist sowohl vorstellbar, daß Mönche sich außerhalb des Klosters der cura animarum widmen, wie auch, daß Laien an Gottesdiensten der monastischen Gemeinschaft teilhaben. Zur Diskussion um die cura animarum durch Mönche siehe ZemLer-Cizewski, How to preach a sermon, S. 409 und Bynum, Docere verbo et exemplo, S. 3 mit Anm. 10.

76 Siehe dazu S. $129 \mathrm{f}$.

77 GuiberT DE Nogent, Autobiographie, III, 13, S. 388. 
re. So verdeutlicht ein Wunder des heiligen Edmund, daß der Heilige nicht duldet, daß sein unversehrter Körper untersucht werde. Im folgenden Wunder befreit der Heilige ein hinkendes Reh von seinem Leiden. Guibert kommentiert die beiden Episoden, indem er darauf hinweist, daß der Heilige, der zugunsten eines Tieres interveniert, um ein Vielfaches großzügiger auf Bitten von gläubigen Menschen eingehen kann ${ }^{78}$. Das Thema der Grabesruhe von Heiligen wird hier, im Gegensatz zum Reliquientraktat, nicht ausgeführt. Das Thema von unbewußten und bewußten gläubigen Empfängern von Wundern, auf das in den Monodiae angespielt wird, ist im Reliquientraktat breiter abgehandelt.

Als stark im Wunderwirken und schnell im Heilen beschreibt Guibert auch die heiligen Swithun von Winchester und Leodegar, wobei er für Leodegar ein Wunder erzählt, das er selbst erlebt hat ${ }^{79}$. Daß dieses selbst erlebte Wunder fast am Ende der Monodiae steht, markiert nach Michel Zink die erneute Präsenz Guiberts in seinem Werk, nach Jay Rubenstein eine unmittelbare Erfahrung der Kraft Gottes in seiner eigenen Jugendzeit ${ }^{80}$. Ein Wunder des heiligen Arnulf an einem adeligen Cousin in seinem Heimatort kommentiert Guibert damit, daß der Geheilte und dessen Nachkommen alljährlich am Fest des Heiligen den anwesenden Klerikern Zuwendungen machten ${ }^{81}$.

Die Heilige, zu deren Verehrung Guibert vordringlich aufruft, ist jedoch Maria. Sie beweist ihre Wunderkraft sowohl gebunden an das Kloster Nogent, an den Schrein der Kathedrale von Laon wie auch unabhängig von Marienheiligtümern. So wird sie auch zum Schluß des Werkes noch einmal rettend aktiv und von Guibert gemeinsam mit dem heiligen Dionysius als Patronin des Werkes am Schluß genannt: Excellentissimam igitur Mariam, coelorum ac terrae patronam, cum Dionysio totius Franciae domino, libri ponamus clausulam ${ }^{82}$.

${ }^{78}$ Ibid. 20, S. 460. Siehe zur ersten Geschichte unten, S. 182, und Kap. 3.2.3.

79 Ibid. III, 20, S. 462 und 464. Zum Leodegar-Wunder siehe oben, S. $41 \mathrm{f}$.

80 Zink, Subjectivité littéraire, S. 198. Guibert ist im dritten Buch aber nicht erst in diesem letzten Kapitel, sondern auch schon während der Ereignisse in Laon wiederholt präsent. Rubenstein, Principled passion, wertet die Episode zudem in bezug auf Guiberts Stellung zur Kirchenreform aus.

81 Guibert De Nogent, Autobiographie, III, 20, S. 462.

82 Ibid. III, 20, S. 468. 


\subsection{Wundererzählungen im Reliquientraktat}

\subsubsection{Stellung der Wundererzählungen}

Der Reliquientraktat De sanctis et eorum pigneribus ist ein ebenso polemisches wie spirituelles Werk, das in vier Bücher aufgeteilt ist. Im Gegensatz zu den Monodiae ist die Handschriftengrundlage des Reliquientraktates zuverlässig83. Die Wundererzählungen finden sich im ersten und im dritten Buch des Traktats. Guibert fügt jedoch im Reliquientraktat nicht annähernd so viele Wunder ein wie in den Monodiae. Im ersten Buch des Traktats thematisiert Guibert die Mißbräuche des Reliquienkults und versucht, dessen Rolle in der christlichen Lehre zu erfassen und Anleitungen zum Umgang mit Heiligen und Reliquien zu bieten. Dies kann als Versuch aufgefaßt werden, das zu Anfang des Traktats beklagte Fehlen regulierender Texte zum Reliquienkult auszugleichen. Wundererzählungen werden teilweise ausführlich wiedergegeben, teilweise nur kurz erwähnt oder angedeutet. Innerhalb dieses ersten Buches findet sich der Großteil der Erzählungen im Exkurs über Wunder. Diese spielen als Kriterien der Heiligkeit in Guiberts Argumentation eine große Rolle. Einzig ein Wunder des heiligen Edmund ist als Einleitung des abschließenden Gedankens des ersten Buches gesetzt, das die Mißbräuche des Heiligenkultes thematisiert. Wundererzählungen sind oft als zeitgenössische Beispiele in $\mathrm{Zu}$ sammenhang mit Beispielen aus der Bibel, klassischer Literatur oder Kirchenvätertexten gestellt.

Im dritten Buch, das sich gegen die Mönche von Saint-Médard und ihren Reliquienbesitz wendet, erwähnt Guibert deren Wunderbuch und zitiert daraus Wundererzählungen, um ihre Falschheit argumentativ zu beweisen ${ }^{84}$.

\subsubsection{Funktionen von Wundererzählungen: exemplarische und ironische Textelemente}

\section{Wundererzählungen als Exempla}

Im Reliquientraktat läßt sich keine Scheidung zwischen Haupthandlung und Exkursen vornehmen, wie dies für die Monodiae gezeigt wurde. Die Episoden sind hier in eine argumentative Abhandlung eingebettet und so als argumentative Beispiele $\mathrm{zu}$ betrachten. Ihre Funktion ist weniger eine didaktische denn eine persuasive. So beschreibt auch Jay Rubenstein die Methode Guiberts als Konstruktion von Argumenten mit Hilfe von Anekdoten ${ }^{85}$. Diese Anekdoten sind oft nur ein Bestandteil des jeweiligen Arguments. Gemeinsam mit Zitaten aus der Bibel oder aus Werken der Kirchenväter tragen die

83 Siehe oben, S. 31 .

84 Guibert DE NoGent, Quo ordine, P, II, Z. 528-615.

85 Rubenstern, Guibert of Nogent, S. 125. 
oft zeitgenössischen Wunder zur Effizienz des Argumentes bei. Die Wunder sind so Teil einer Argumentation, deren Funktion die Verdeutlichung von allgemeiner formulierten Überlegungen ist. Als Beispiel soll die Verwendung des gleichen Edmund-Wunders betrachtet werden, das in den Monodiae Teil eines assoziativ-digressorisch verbundenen Wunderexkurses ist. Dieses Wunder ist im Reliquientraktat Teil der Erörterung, wie das Problem des Mißbrauchs von Reliquien zu lösen sei. Guibert entwickelt das Hauptargument, daß die Wahrung der Grabesruhe von Heiligen viele Mißbräuche verhindern würde, auf ausführliche Weise. An den Anfang setzt er das Bibelzitat terra es et in terram ibis (Gen. 3, 19) ${ }^{86}$. Auf polemische Weise kreiert er eine Art Gegenzitat, das als direkten Angriff auf die Praxis des Reliquienkults verstanden werden muß: Gott habe nicht gesagt: aurum vel argentum es, in aurum vel argentum ibis ${ }^{87}$. Nach seiner Kenntnis würden sich seit frühester Zeit nicht einmal die stolzesten Könige in goldenen oder silbernen Kästen beerdigen lassen $^{88}$. Nach einem weiteren Bibelzitat bietet Guibert zum ersten Mal seine Lösung der beschriebenen Mißbräuche an: Die Wahrung der Grabesruhe der Heiligen $^{89}$. Nach der weiteren Entwicklung des Argumentes durch Bibelzitate führt Guibert Gregor den Großen als Quelle des Diktums an, daß schwer bestraft würde, wer unwissend die Körper des heiligen Paulus und Laurentius schaue ${ }^{90}$. Als Moralist gibt Guibert zu bedenken, wie sehr Geiz als Motiv dieser Handlung die Strafe verschärfen würde. Dazu verweist er auf die Tradition, Körper von Heiligen überall zu verstreuen oder wegen der Oblationen täglich zur Schau zu stellen ${ }^{91}$. Wiederum werden Argumente aus der biblischen Tradition angefügt. Danach kündigt Guibert an, mehrere warnende Beispiele (documenta) einzufügen, die bewiesen, daß Heilige auf solche Eingriffe ungehalten reagierten. Das erste Zeugnis stammt aus dem gleichen Brief Gregors des Großen, der kurz zuvor angeführt wurde. Gregor habe auf Anfrage nicht gewagt, den Kopf des Apostels Paulus der Tochter des Tiberius zu geben $^{92}$. Darauf wird die Geschichte der frevelhaften Überprüfung des Leibes des heiligen Edmund angeführt, als schlagendes Argument dafür, daß Heilige

86 Guibert de Nogent, Quo ordine, P, I, Z.607. Siehe dort auch die Anmerkung zur Abweichung gegenüber dem Vulgata-Text.

87 Ibid. P, I, Z. 608-609. Michele C. Ferrari vermutet in der Einleitung zu Thiofridi AbBatis ECHTERnACHENSIS, Flores epytaphii, S. XXVII, daß dieser Ausspruch am ehesten eine Reaktion auf den Traktat des Thiofrid darstelle. Daß direkte Bezüge zwischen den zwei Werken schwierig herzustellen sind, wurde oben, S.39, gezeigt.

88 GUIBERT DE NOGENT, Quo ordine, P, I, Z. $624 \mathrm{f}$.

89 Ibid. P, I, Z. 631-633: Certe si sanctorum corpora sua iuxta naturae debitum loca, id est sepulchra, servassent, huiusmodi quos retexui errores omnino vacassent.

90 Ibid. P, I, Z. 647f. Gregor der Große, Brief 4, 30, ed. in: Gregorius Magnus, Registrum, S. 248-250.

91 Guibert de Nogent, Quo ordine, P, I, Z. 649-651. Schon in den Monodiae erwies sich Geiz als eines der Laster, vor dem Guibert mittels Wundererzählungen eindringlich warnte, siehe oben, S. $175 f$.

92 Guibert de Nogent, Quo ordine, P, I, Z. 683-686. 
diese Drohung wirklich wahr machen, trugen doch der fehlbare Abt und sein Komplize von ihrer frevlerischen Tat Lähmungen an den Händen davon ${ }^{93}$. Abgeschlossen wird der Argumentationsstrang mit der nochmaligen Erwähnung des Lösungsvorschlags, die Grabesruhe der Heiligen beizubehalten. Dies in einem kunstvollen, rhythmischen Satz:

"Wenn es derart künftig jedem gestattet wäre, ruhig in seinem Grab zu liegen, würde jeder Streit über einen Wechsel oder Tausch heiliger Leiber oder von Überresten von Heiligen verstummen, und es würden nicht diese behaupten, sie besäßen jenen, jene diesen Heiligen, wenn, wie es recht und billig wäre, die Gräber von allen unversehrt blieben, und wenn alle in der Erde, die ihnen zugewiesen wurde, ungestört ruhen dürften, entstünden die Betrügereien, wie wir solche vorhin erwähnt haben, über deren vielfache Verteilung nicht, und es würden nicht Unwürdige die Plätze von Würdigen einnehmen. $\ll^{94}$

Die Argumentation von Guiberts Wunderexkurs ist rund um vier zeitgenössische Wundererzählungen als Exempla angeordnet ${ }^{95}$. Am ersten Exemplum, einem Eucharistiewunder aus Soissons, lassen sich beispielhaft verschiedene Deutungsebenen dieser Wundererzählungen aufzeigen: Ein unschuldiger Knabe sieht bei seinem erstmaligen Besuch der Messe, wie der Priester während der Wandlung anstatt der Hostie ein Knäblein in die Höhe hebt ${ }^{96}$. Diese Erzählung hat in der Argumentation des Wunderexkurses die Funktion, aufzuzeigen, daß Gott Wunder durch unbeteiligte Mittler wirken kann. Das Wunder soll auf den Knaben, der sich kaum mehr daran erinnern konnte, keinen Einfluß gehabt haben. Das Zeichen wurde einzig zur Erbauung des Glaubens der Anwesenden gewirkt. Neben dieser Funktion des Exemplums, die Guibert selbst nennt, ist die Erzählung durch ihre Aussage mit einem wichtigen Thema des Reliquientraktats, dem Abendmahlsstreit, verbunden. Das Beispiel kann dahingehend gedeutet werden, $\mathrm{da} \beta$ es zeigen soll, daß Guiberts Ansicht konform ist zur Orthodoxie: Christus ist substantialiter anwesend in Brot und Wein ${ }^{97}$. Das Beispiel ist daher mehrdeutig. Die erste Deutungsebene wird in den Kommentaren entwickelt: Die Erzählung ist ein Beispiel für ein Wunder durch unbeteiligte Mittler. Die zweite Deutungsebene wird nicht explizit gemacht. Das Beispiel, das die orthodoxe Ansicht im Abendmahlsstreit

93 Ibid. P, I, 686-696. Zur Edmund-Geschichte siehe oben, S. 179, Anm. 78.

94 GUIBERT DE NOGENT, Quo ordine, P, I, 696-702: Si sic quietum suis tumulis fore quenque liceret, super corporum pignerumve sacrorum mutatione sive concambio altercatio tota sileret, nec ii illum, illi eundem habere se dicerent si illibata universorum, ut iustum esset, monumenta manerent, et dum omnes in sibi attibuta terra immoti quiescerent, fraudes quas prelibavimus super eorum multifida distributione non fierent nec indigni dignorum loca tenerent.

95 Zum Wunderexkurs siehe oben, S. 49-53.

96 Guibert De NoGent, Quo ordine, P, I, Z. 178-196.

$97 \mathrm{DaB}$ die Eucharistie für den Moraltheologen Guibert ein schwieriges Thema war, das ihn ins Feld der spekulativen Theologie fuhrte, zeigt RubensteIn, Guibert of Nogent, S. 132-172, hier S. 133. 
verdeutlicht, wird erst in Zusammenhang mit den großen Themen des Traktats verständlich.

Wundererzählungen als polemische und ironische Textelemente ${ }^{98}$

Wenn Guibert die Wundererzählungen im ersten Buch als argumentative Exempla einsetzt, die Bestandteile von Argumentationsketten sind, kann davon ausgegangen werden, daß er sie ohne ironischen Hintersinn verwendet. Im dritten Buch jedoch sind die Wunder des Mirakelbuchs der Mönche von SaintMédard angeführt. In diesem Buch wird der Angriff gegen die Mönche und deren eine Reliquie, den Milchzahn Christi, geführt. Ausgewählte Wunder des Mirakelbuchs werden hier als Teil der Polemik eingesetzt, zitiert und entgegen ihrer ursprünglichen Intention verwendet. Das Ziel Guiberts ist die Entlarvung der Wunder als Beweise für die Echtheit der angegriffenen Reliquie, den Milchzahn Christi. Er verwendet für seine Beweisführung mehrere Strategien. Das erste angegriffene Wunder handelt vom Reliquienkästchen des heiligen Zahns. Kapellane Ludwigs des Frommen, so gibt Guibert die Episode aus dem Wunderbuch der Mönche wieder, hätten die Existenz des Milchzahns Christi bezweifelt ${ }^{99}$. Während einer Messe habe sich das Reliquienkästchen in die Höhe gehoben. Dies sei den Umstehenden Beweis für die Echtheit des Inhalts gewesen. Der Angriff auf das Gesagte ist hier direkt: Eine Folge von rhetorischen Fragen zeigt die Schwäche der Argumentation im Wunderbuch: $\gg$ Aber welcher, so frage ich, Beweisgrund? Welche, so frage ich, himmlische Stimme, welcher Engel, so bitte ich, hat herabgedonnert, daß dies der Zahn des Retters sei, den er als zarter Junge verloren hat? «100

Danach folgen Argumente, welche die Glaubwürdigkeit des Wunders unterminieren. So macht Guibert die Überlegung, da $\beta$, wenn das Kästchen sich sozusagen vom heiligen Altar in die unheilige Luft geflüchtet hätte, dieses doch gezeigt hätte, daß es die Heiligkeit des Altars nur ungeduldig ertragen hätte $^{101}$. Die Erzählung läßt absurde Auslegungen zu, ist daher zweifelhaft.

Im Falle der Geschichte des ertrinkenden Mönches wendet Guibert mehrere Strategien an. Erst führt er, wie in der Kästchen-Geschichte, den direkten Angriff durch die rhetorischen Fragen. Dann entzieht er der Geschichte das

98 Es wird im folgenden von einem rhetorischen Ironie-Begriff ausgegangen. Ironie wird als Form von »uneigentlichem Sprechen « verstanden, wo das »eigentlich Gemeinte hinter dem tatsächlich Gesagten durchsichtig « bleibt, OTTMER, Rhetorik, S. 178. Rezipienten des Textes können Ironie durch sprachliche Signale erkennen. Ironie geht davon aus, daß verschiedene Gruppen von Rezipienten die Aussagen unterschiedlich verstehen können. Siehe ibid. S. 177-179.

99 Zum Vergleich von Guiberts Version und den Mirakelbüchern aus Saint-Médard siehe unten, Kap. 5.1.3.

100 Guibert DE Nogent, Quo ordine, P, III, Z.537-540: Sed quod, queso, argumentum? Quae superna, queso, vox, quis, precor, angelus detonuit dentem Salvatoris hunc esse, quem tenellus ediderit?

101 Ibid. P, III, Z. 550-553. 
zeitliche Schema, das sie in der Version des Wunderbuches aufwies ${ }^{102}$. Zudem spielt er mit den Quellenangaben der Geschichte. Indem er dieses Spiel am Höhepunkt der Erzählung, der wunderbaren Erscheinung der Heiligen, einführt, gibt er sie der Lächerlichkeit preis: »Aber dem Abt, wie jene Schrift berichtet, ist ich weiß nicht welcher der Heiligen daselbst erschienen und hat ihm, wie gesagt wird, gesagt: $[. ..] \ll^{103}$

Im Wunderbuch von Saint-Médard hingegen sind die Heiligen, die dem Abt erscheinen, genau genannt: Sebastian, Gregor, Medardus und Gildardus, die Hauptheiligen des Klosters. Die Geschichte ist klassisch aufgebaut und verwendet gut bekannte Topoi aus der Mirakelliteratur, beispielsweise das Geschehen in der Nacht, das Erscheinen der Heiligen in einer Vision, der Umstand, daß erst nach wiederholter Mahnung dem Willen der Heiligen Folge geleistet wird.

Guibert spielt also mit den hagiographischen Konventionen, Wundertäter und Zeugen der Ereignisse zu nennen. Daß das Wunder Guiberts Mißfallen erregte, läßt sich gut nachvollziehen. Schon in den Monodiae werden der Tod von unbotmäßigen Mönchen und das Schicksal ihrer sterblichen Überreste thematisiert. In diesen Episoden wird solchen Mönchen jeweils ihre entsprechende Strafe erteilt, sei es, daß sie von Dämonen geholt oder außerhalb des Friedhofs vergraben werden ${ }^{104}$.

Zur Reliquienreise der Kleriker von Laon hat Guibert ebenfalls ein gespaltenes Verhältnis. Während seine Kritik in den Monodiae nur verhalten aufscheint, schlägt er einige Jahre später im Reliquientraktat deutlichere Töne an.

So führt er in den Monodiae die Reliquienreise und die Wunder, die anläßlich dieser Kollektenreise geschahen, mit leichter Kritik ein: Interea secundum qualemcumque morem ad corrogandas pecunias coeperunt feretra et sanctorum reliquia circumferri ${ }^{105}$. Die ersten zwei Wundererzählungen zeugen von Guiberts ironischem Blick auf diese Kollektenreisen. Die erste Erzählung richtet sich gegen den Sprecher der Gruppe. Dieser habe verkündet, obwohl er nicht wirklich daran geglaubt habe, daß die Marienreliquien einen Kranken heilen könnten. Nachdem ein Taubstummer geholt war, wurde den Klerikern angst und bange, glücklicherweise funktionierte aber das Wunder ${ }^{106}$. Die Rolle des ersten Priesters und seiner Kleriker wird ironisiert und damit kritisiert. Mit dem festen Glauben der Geistlichen - einer wichtigen Voraussetzung für ein

102 Siehe oben, S. $143 \mathrm{f}$.

103 GUIBERT DE NOGENT, Quo ordine, P, III, Z. 596f.: Sed abbati, ut pagina illa refert, nescio quis sanctorum inibi, ut dicitur, apparuit eique, ut dicitur, dixit: [...].

104 Siehe dazu oben, S. 176f. Zur Rolle von Heiligen im Moment des Todes und des Gerichts siehe PhiliPPart, Vivants, dort: Patrons de la bonne mort, S. 87-96.

105 Guibert de Nogent, Autobiographie, III, 12, S. 378.

106 Ibid. III, 12, S. 380: Dici non potest ab aliquo sub quanto periculo et angore tunc clerici constiterunt; at, cum altis communem dominam cum suo unico Jesu Domino exorantes suspiriis, epotis sacris aquis, interrogatur a trepidante presbytero nescio quod verbum. 


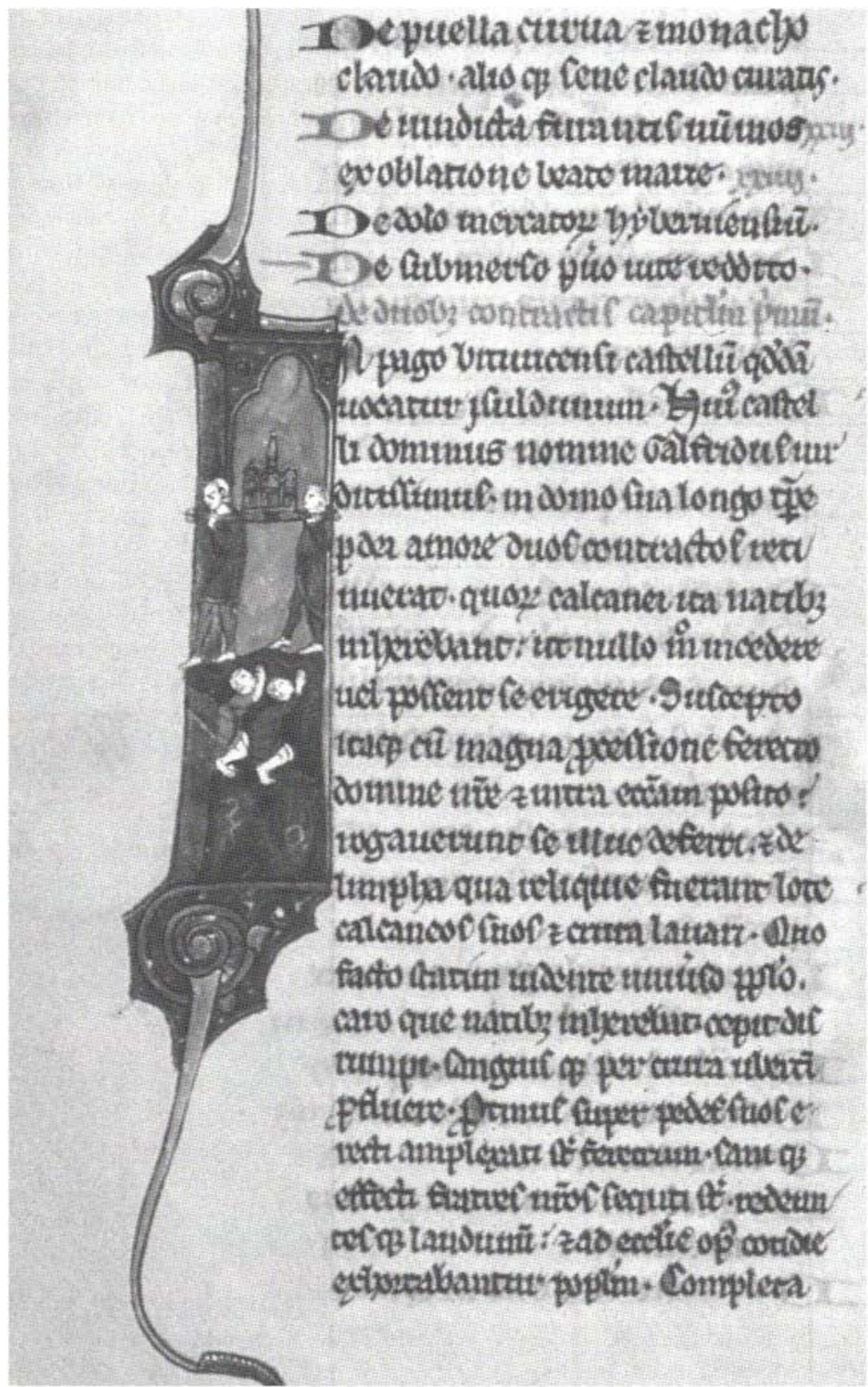

Abb. 3: Miniatur mit der Darstellung der Reliquienreise der Kleriker von Laon.

Bibliothèque nationale de France, lat. 17491, fol. $92 \mathrm{v}$. 
Wunder - ist es nicht weit her. Obwohl das Wunder funktioniert und der Taubstumme geheilt wird, ist die Kritik an diesem erzwungenen Beweiswunder zumindest auf den zweiten Blick unübersehbar. In anderen hagiographischen Berichten über analoge Fälle des Umgangs mit Heiligkeit werden nämlich anfängliche Zweifel bald von Gewißheit verdrängt und das Ereignis durch Gebete und Fasten vorbereitet. Auf diese Weise schildert beispielsweise Haymo die Öffnung des Heiligenschreins im Kloster Saint-Denis 1053 anläßlich des Streits mit den Mönchen von St. Emmeram aus Regensburg um den Leib des heiligen Dionysius ${ }^{107}$.

Auch das zweite erwähnte Wunder, das in Angers geschehen sein soll, weist den gleichen ironischen Unterton auf. Das Wunder, die Befreiung einer dikken Frau von ihrem zu klein gewordenen Ehering, spielt sich just im Augenblick des Niederlegens der Gaben ab. Die Leute bringen darauf in großer Zahl Geld, die Frauen vor allem Halsketten und Ringe. Wie Gabriela Signori dargelegt hat, gibt Guibert durch die Ausgestaltung der Geschichte Hinweise auf den ironischen Hintersinn der Darstellung und damit auf seine kritische Haltung gegenüber den Kollektenreisen ${ }^{108}$.

Im Reliquientraktat spricht Guibert seine Kritik an den Klerikern aus Laon deutlicher aus. Dies zeigt sich im doppelsinnigen ersten Satz: Celeberrima quaedam ecclesia huiusmodi circunvagationes agebat $[. . .]^{109}$. Die ironische Distanzierung von den Klerikern zeigt sich darin, daß Guibert den Namen der gewißen, äußerst berühmten Kirche nicht nennt, obwohl er sich selber als in die Ereignisse involviert darstellt. In seinen Schlußbemerkungen übt Guibert dann offen Kritik und wirft den Klerikern vor, vom christlichen Glauben Abweichendes zu verkünden ${ }^{110}$.

Diese zwei Beispiele haben gezeigt, daß Ironie im Reliquientraktat ein von Guibert wiederholt verwendetes Instrument ist, um Distanz oder Mißbilligung zum Berichteten zu signalisieren. Ironie kann so als Vorstufe zur offenen Polemik verstanden werden und geht zuweilen fließend in diese über.

107 Grosse, St. Denis, S. 20. Guibert berichtet von einem ähnlichen Streit der Mönche von Saint-Denis und Gottfried von Amiens um den Leib des heiligen Firminus. GuIBERT DE Nogent, Quo ordine, P, I, S. $103 \mathrm{f}$.

108 SigNORI, Maria, S. $110 \mathrm{f}$.

109 Guibert de Nogent, Quo ordine, P, I, Z. $403 \mathrm{f}$.

110 Ibid. P, I, Z. 415-418. 


\subsection{Wundererzählungen im Marienlob De laude sancte Marie}

\subsubsection{Stellung der Wundererzählungen}

Das Marienlob ist ein uneinheitliches Werk, das von der Forschung bislang wenig beachtet wurde. In dieser Schrift sind Materialien zur Marienverehrung zusammengestellt. Guibert bietet in einem ersten Teil Auslegungen zu biblischen Stellen, die mit der Gottesmutter Maria in Beziehung stehen. So bietet er längere Auslegungen zu 1. Reg. 10, 18 (Salomons Thron aus Elfenbein), Ezech. 40-44 (Beschreibung des Tempels) und Luc. 10, 38-42 (Martha und Maria). Diese letzte Perikope ist zum Fest von Mariä Himmelfahrt zu lesen ${ }^{111}$. Zudem zählt Guibert Horen des Marienfestes auf ${ }^{12}$. Gegen den Schluß dieser Zusammenstellung findet sich auch ein Block von drei Wundererzählungen, gefolgt von weiteren Auslegungen von Stellen aus den Psalmen und anderen biblischen Büchern. Den Schluß des Marienlobs bildet ein Gebet in Versform.

Bei den hier interessierenden Wundererzählungen handelt es sich um drei längere Episoden, wovon die dritte die kürzeste ist. Dieser Block von Wundererzählungen wird eingeführt mit allgemeinen Überlegungen zu Marienwundern. Die drei Berichte sind in der Handschrift Berlin Phillipps 1695 sowohl von der Einleitung als auch untereinander, und vom nachfolgenden Text durch Initialen abgetrennt. Innerhalb des Traktats, der in der Handschrift auf den foll. 52r-84r zu finden ist, nehmen die Wundererzählungen die foll. 73r80v ein. Diese drei Episoden stellen nur einen kleinen Teil des Traktats dar, sind aber als einheitliche Gruppe zu behandeln, die sich vom Rest des Textes durch ihre Ausrichtung deutlich unterscheidet. Sie werden durch eine einleitende und eine abschließende Bemerkung als Exkurs markiert. Guibert führt die Gruppe ein mit der Bemerkung: »Da ich denn also zu verstehen geben wollte, wie groß sie ist (Maria, Anm. K. F.) und wie sie seit alters durch Ruhmestitel geoffenbart worden ist, ist es am Platze, daß wir auch das einflechten, was sie zu unserer Zeit vollbracht hat «113. Nach einer Bemerkung, die den Exkurs der drei Wundererzählungen abschließt, nimmt Guibert den Faden des Marienlobes wieder auf: »In Anbetracht jener so bereitwillig angenommenen Opfergaben der sündigen Seele, in Anbetracht des Heils auch für den Leib,

111 Palazzo, Johannson, Jalons liturgiques, S. 33 und Iogna-Prat, Culte de la vierge, S. 92. Sie wird in Predigten des 12. Jahrhunderts immer wieder kommentiert.

112 Eine genaue Analyse und Einordnung des Marienlobs steht noch aus. Zum Stundengebet siehe HäussLING, Art. "Stundengebet $\ll$.

113 GuIBERT DE Nogent, De laude, Sp. 564: Igitur quoniam quanta sit, quantumque veteribus portensa praeconiis significare voluimus, dignum est etiam ut quae nostra aetate peregerit intexamus. 
worin nichts als das allgemeine Heil der Seele erstrebt wird, wollen wir die Rede erneut auf ihr Lob richten «114.

\subsubsection{Funktionen der Wundererzählungen: Aktuelle Beweise der Größe Mariens}

Die drei Wundererzählungen des Marienlobs sollen im Rahmen des übergeordneten Themas zeitgenössische Beispiele der Größe Mariens geben. Alle drei Erzählungen, die in Marienmirakelsammlungen, Chroniken, Exemplaund Legendensammlungen überliefert sind, verdeutlichen die gleiche Botschaft: Reuigen Sündern ist der Beistand der Gottesmutter gewiß. Zwei Frauen und ein Mann begehen je eine Sünde, worauf sie aufgrund ihrer Reue, Beichte oder ihres Bittgebets errettet werden. Das Thema wird so anhand von drei Beispielen variiert.

In der ersten Episode, die in der Diözese Laon spielt, steht ein Verwandtenmord im Zentrum ${ }^{115}$. Sie sei im folgenden kurz zusammengefaßt: Eltern, Tochter und Schwiegersohn wohnen unter einem Dach. Da sich die Schwiegermutter besonders liebevoll um ihren Schwiegersohn kümmert, kursiert auf Anstiften des Teufels bald das Gerücht des Ehebruchs. Anstatt die Haushalte zu trennen, was laut Guibert genügt hätte ${ }^{116}$, beschließt sie, den jungen Mann umzubringen. Dies geschieht mit Hilfe von zwei jungen Männern. Nach dem Begräbnis legt die Mörderin jedoch bei ihrem Priester die Beichte ab. Dieser macht ihr anläßlich eines Streites ihre Tat offen zum Vorwurf, worauf die Eltern des jungen Mannes die Frau vor das bischöfliche Gericht in Laon bringen $^{117}$. Sie wird zum Tod durch Verbrennung verurteilt. Vor der Exekution bekennt sie in der Marienkathedrale vor einer großen Menschenmenge ihre Schuld und erbittet den Beistand der Gottesmutter. Während der Exekution geschieht das Wunder: Inmitten des Feuers bleibt die Sünderin unverletzt, auch Stockschläge der Familie des Schwiegersohnes können ihr nichts anhaben. Der Viztum führt die Frau wieder zurück nach Laon, wo sie in der Kathedrale in der jubelnden Menge der Gottesmutter dankt. Anschließend führt er sie nach Hause, wo sie nach drei Tagen stirbt. Die Beichte der Untat und die Bitte um den Beistand Mariens haben zur wunderbaren Errettung der Sünderin aus den Flammen geführt.

114 Ibid. Sp. 574: Pro iis itaque peccatricis animae devotionibus tam liberaliter acceptatis, pro salute etiam corporum in quibus non quaeritur nisi communis sospitas animarum, ad ipsius laudem iterum vertamus articulum.

115 Ibid. Sp. 564-568. Eine ausführliche Zusammenfassung und Analyse der Episode bei KaISER, Verbrechen und Strafe, S. 91-93.

116 Guibert de Nogent, De laude, Sp. 565.

117 Der Bischof hatte innerhalb seiner Grundherrschaft die hochgerichtliche Kompetenz. Siehe dazu KaISER, Verbrechen und Strafe, S. 100. 
Hermann von Tournai überliefert in seinem Mirakelbuch die gleiche Erzählung mit leichten Abweichungen ${ }^{118}$. Die größte Abweichung betrifft die Aufdeckung des Verbrechens. Bei Hermann bricht der Viztum den schon verschlossenen Sarg noch einmal auf, untersucht die Angelegenheit in kriminalistischer Manier und findet an der Leiche Spuren des Mordes. In der Version Guiberts hingegen ist die Frau geständig und wendet sich an ihren Pfarrer als Vertreter der kirchlichen Autorität und legt über das Verbrechen die Beichte ab ${ }^{119}$. Hermann betont weniger die Beichte beim Priester, als vielmehr die Findigkeit des Viztums, die zur Aufdeckung der Tat führt. Ist es bei Herrmann der Stellvertreter des Bischofs, der das Geständnis der Frau provoziert, ist sie bei Guibert aus eigenem Antrieb geständig und wendet sich von sich aus an die kirchliche Autorität. Nach beiden Versionen wirkt Maria das Wunder aufgrund der öffentlichen Beichte der Frau in der Marienkathedrale. Das für alle sichtbare Wunder kann als äußerliches Zeichen der Gnade Gottes, die wahre Reue der Sünderin, interpretiert werden ${ }^{120}$.

In der zweiten Episode, deren Inhalt oben wiedergegeben ist, steht ein gemeinsames Erlösungswunder Mariens und des Märtyrers Hippolyt im Zentrum $^{121}$. Diese heilen die Folgen eines Strafwunders infolge Festtagsentheiligung. Auch in dieser Geschichte geschieht die wunderbare Heilung aufgrund des fortgesetzten Gebets des Geschädigten. Dieser betet erst in einer Kirche der heiligen Magdalena, da er deren Festtag verletzt hat. Danach läßt er sich in eine Marienkirche bringen, um dort zu beten. Die Heilung tritt jedoch erst ein, nachdem der Kranke von einem Adeligen gütig aufgenommen worden ist. Der Geschädigte wird noch nicht vollständig geheilt. Erst nach einem Jahr, während dessen er lebendiger Beweis des Wunders und der Größe Mariens ist, führen die beiden Heiligen das Wunder ganz zu Ende. Weshalb die Gnadentat geschieht, macht Guibert für diese Geschichte nicht explizit. Vermutet werden kann, daß sie aufgrund des unermüdlichen Gebets und der Anrufung gewirkt wird. Die wunderbare Heilung tritt unabhängig von einem sakralen Ort ein.

In der dritten Episode ist wiederum das Thema der Anbetung Mariens zentral ${ }^{122}$. Die Hauptperson ist eine Ehebrecherin, die ein Verhältnis mit einem verheirateten Mann hat. Gleichwohl richtet sie täglich ein Ave Maria an die Gottesmutter. Die geprellte Ehefrau bittet Maria um Strafe ihrer Nebenbuhlerin. Diese erscheint ihr in einer Vision und bekundet, daß sie nichts gegen

118 Hermann von Tournai, De miraculis sanctae Mariae Laudunensis, III, 27, Sp. 1008-1011.

119 Guibert De Nogent, De laude, Sp. 566. Der Priester spielt allerdings eine zwiespältige Rolle, da er anläßlich eines Streites mit der Frau die Tat bekannt macht.

120 Ich danke Christine Wetli für den Hinweis auf den Zusammenhang von innerer conversio als Gnade Gottes und deren äußerem Zeichen des Wunders. Schon bei Augustin und Gregor dem Großen werden Reue und Buße als Wunder, als Akt göttlicher Gnade, bezeichnet, siehe oben, S. 61 .

$121 \mathrm{Zu}$ dieser Erzählung siehe oben, S. 73-75, und unten, Kap. 5.2.3.

122 GuiberT de Nogent, De laude, Sp. $573 f$. 
die Nebenbuhlerin tun könne, da diese sie täglich verherrliche. Darauf begegnet die Ehefrau, enttäuscht von Marias Antwort, der Nebenbuhlerin und konfrontiert diese damit, daß sie ihrer Seele Schmerzen zufüge. Sie habe bereits Maria angerufen, welche aber wegen des täglichen Lobes nichts gegen die Sünderin tun wolle. Diese entscheidet sich darauf zur Umkehr und lebt fortan keusch. In dieser letzten Variation des Themas verhindert das Gebet zu Maria deren strafenden Eingriff durch ein Wunder. Gewissenserforschung angesichts der Güte der Gottesmutter führt dann aber bei der Sünderin zum Wunder der Umkehr.

Alle drei Wundererzählungen spielen im Milieu der einfachen Leute. Maria steht Bauern und Arbeitern zur Seite aufgrund deren Umkehr, Beichte, Bittgebet und Verehrung. Im vorangehenden Abschnitt, der die aktuellen Beispiele der Güte Marias einführt, wird der Akzent auf Erbauung gelegt, dies in Anspielung auf die Antinomie Glauben/Werke ${ }^{123}$ : „Denn dieselben Wunderzeichen, die in alten Zeiten imstande waren, den Glauben zu stärken, sind auch jetzt noch imstande, ihn, der ohne Werke kaum Bestand hat, wie auch den sittlichen Wandel aufzurichten.«124 Diese Themen - Erbauung, Buße, Beichte - legen den Zusammenhang mit der Seelsorge nahe ${ }^{125}$. Daß die handelnden Personen aus der Welt der Laien stammen, kann ein Hinweis darauf sein, daß diese Erzählungen für Predigten außerhalb des monastischen Publikums gedacht waren. So wird die dritte, kürzeste Episode mit folgenden Worten eingeführt: »Außerdem gibt es noch etwas anderes, was sich kurz erzählen läßt, aber als Beispiel großartig wirkt, und worauf die Ohren aller Sünder gerichtet sein sollen.«126 Diese Einleitung spielt auf die Vermittlung der Geschichte an, als lehrhaftes Beispiel, das auf mündlichem Weg weitergegeben werden kann. Die drei Beispiele aus dem Marienlob Guiberts sind sowohl in den Marienmirakelsammlungen des 12. und 13. Jahrhunderts als auch in Legendensammlungen verzeichnet, die ebenfalls den Zusammenhang der Marienmirakel mit der Predigt nahelegen. Sie sind am ehesten als Predigtexempla im engeren Sinne zu verstehen ${ }^{127}$.

123 Siehe bspw. Iac 2, 14-26; Rom 4, 1-8.

124 GuIBERT DE NOGENT, De laude, Sp. 564: [...] haec eadem namque signa, quae antiquitus fidei aedificandae valuerant, jam nunc eidem sine operibus vix constanti et moribus erigendis valent.

125 Zur cura animarum durch Mönche im 11./12. Jahrhundert siehe oben, S. 178, Anm. 75; zur Predigt siehe Longère, Prédication médiévale, S. 54-68; Dereine, Prédicateurs >apostoliquess.

126 GUIBERT DE NogENT, De laude, Sp. 573: Est praeterea aliud quiddam relatu breve, exemplo magnificum, cui arrigendae sunt aures omnium peccatorum.

127 Vgl. dazu Moos, Geschichte, S. 39-48, mit der Darstellung der Forschungsansätze zum Predigtexemplum. 


\subsection{Wundererzählungen in der Kreuzzugschronik Dei Gesta per Francos}

\subsubsection{Stellung der Wundererzählungen}

Wie Guibert im Vorwort der Kreuzzugschronik darlegt, ist diese Schrift eine Überarbeitung einer einfacher gestalteten Chronik ${ }^{128}$. Guibert folgt deren Chronologie über weite Strecken, überarbeitet sie und fügt Ergänzungen oder Weiterentwicklungen hinzu ${ }^{129}$. Guibert fügt zudem ganze Partien neu hinzu, so das erste Buch und einen großen Teil des siebten Buches (ab Kap. 21). Um die Bedeutung und Funktion von Wundererzählungen zu ermessen, muß als erstes festgestellt werden, ob Guibert einzelne Erzählungen seiner Vorlage entnommen hatte, oder ob die Erzählungen neu hinzugefügt wurden.

In der Kreuzzugschronik spielen einzelne Wundererzählungen eine weit weniger wichtige Rolle als in den Monodiae. Allerdings gibt Guibert der Kreuzzugschronik die Überschrift Dei Gesta per Francos, Taten Gottes durch die Franken. Auch im Vorwort begründet Guibert seine Überarbeitung einer Kreuzzugschronik mit dem Hinweis, daß auf Erden selten mehr wunderbare Dinge, mirabiliora, geschehen seien als zu seinen Tagen ${ }^{130}$. Guibert wagt denn auch im siebten Kapitel einen Vergleich des Kreuzzugs mit den Wanderungen des Volkes Israel im Alten Testament. So seien die Taten der Kreuzfahrer entbehrungsreicher als diejenigen der Angehörigen des Volkes Israel, die mit ihren Frauen und Kindern, mit immer vollem Bauch wanderten und von Engeln und häufigen Wunderzeichen begleitet waren ${ }^{131}$. Auf der Ebene des Kreuzzugsberichts spielen denn Wunderzeichen nur in wenigen, unten beschriebenen Fällen eine entscheidende Rolle für den Fortgang der Unternehmung.

\subsubsection{Funktionen von Wundererzählungen}

Himmelsphänomene als Zeichen für den Fortgang des Kreuzzugs

In den überarbeiteten Teilen von Guiberts Kreuzzugschronik finden sich nur wenige Wunderzeichen. In erster Linie werden Himmelserscheinungen als

128 Siehe dazu oben, S. 33.

129 Die Übereinstimmung der zwei Werke ist in der Edition Huygens auf etwas gewöhnungsbedürftige Weise als Marginalie angegeben. Verzeichnet sind die Abschnitte der Gesta Francorum in der Edition Hagenmeyer, welche die Kapitel zusätzlich in Paragraphen unterteilt. Da diese dort ungefähr gleich lange Textabschnitte beinhalten, zeigt der Abstand zwischen zwei Paragraphen, um wieviel der ursprüngliche Text ergänzt wurde. Siehe GuiberT De NoGent, Dei Gesta, S. 57f. Zur Benützung der Quellen durch Guibert siehe auch Guibert de Nogent, Geste, S. 16-21.

130 Guibert de Nogent, Dei Gesta, S. 80.

131 Ibid. VII, 21, S. 305. Zur Einordnung dieser Passage, die Teil einer längeren Exegese aus dem Propheten Sacharja ist, siehe Rubenstein, Guibert of Nogent, S. 100f. 
Zeichen für den Fortgang der Unternehmung gedeutet. Anläßlich der ersten Erwähnung von Himmelszeichen bemerkt Guibert, daß es in historiographischen Werken üblich sei, solche Zeichen zu vermerken ${ }^{132}$. Zeichenhafte Erscheinungen nennt er anläßlich von Beratungen der Großen vor dem Beginn der Unternehmung ${ }^{133}$. Diese sind in der Vorlage des Anonymus nicht erwähnt, sondern sind von Guibert dem Bericht hinzugefügt worden ${ }^{134}$.

Weitere Himmelszeichen erwähnt Guibert zur Belagerung von Antiochia durch die Türken ${ }^{135}$. Ein Feuer sei vom Himmel ins Lager der Türken gefallen, dann aber von den Kreuzfahrern anders als von den Türken interpretiert worden. Dieses Feuer wird schon in der Vorlage, der anonymen Chronik, erwähnt, allerdings ohne den Hinweis auf die unterschiedlichen Deutungen der Erscheinung durch die beiden Parteien ${ }^{136}$. Während in der Vorlage auf ähnliche Weise wie bei Guibert vermerkt ist, daß beide gegnerischen Parteien gestaunt hätten über die Himmelserscheinung und die Türken ihr Lager verschoben hätten, bietet nur Guibert die belehrende Bemerkung, daß das Wunderzeichen den Feinden bei richtiger Interpretation ihr Unglück angekündigt hätte ${ }^{137}$. Diese Erwähnung von verschiedenen Deutungen der Gemeinschaften zeugt von seinem Bewußtsein, daß die Interpretation von Zeichen an Gemeinschaften gebunden war. Die Türken sollen das Feuer als Zeichen für die schlechte Wahl ihres Lagerplatzes gedeutet und daraufhin ihr Lager verschoben haben. Dahingegen wußte Guibert rückblickend aus der Warte des Geschichtsschreibers, daß dieses Feuer als Zeichen für den Untergang der türkischen Armee hätte gedeutet werden müssen. Das Zeichen, als miraculum und portentum bezeichnet, erhält in Guiberts Bericht eine wichtige Funktion für den Verlauf des Kreuzzugsberichts ${ }^{138}$.

In Bezug auf weitere Himmelserscheinungen bezieht sich Guibert in seinem neu eingefügten siebten Buch auf die Chronik des Fulcher von Chartres.

132 Guibert de Nogent, Dei Gesta, II, 17, S. 134.

133 Ibid. II, 17, S. 133f. Siehe dazu oben, S. 55.

134 Bibl. Angaben der Version siehe Anm. 133; die Korrespondenz mit der Vorlage Guiberts: Anonymi Gesta Francorum, 3, 2, S. 132-137.

135 Guibert de Nogent, Dei Gesta, V, 22, S. 224f.

136 Anonymi Gesta Francorum, 26, 4, S. 350: Nocte quippe superveniente ignis de caelo apparuit ab occidente veniens et appropinquans cecidit intra Turcorum exercitus, unde mirati sunt et nostri et Turci. Mane autem facto tremefacti Turci fugerunt omnes pariter pro ignis timore ante domini Boamundi portam, illicque hospitati sunt. Hagenmeyer vermutet, daß diese Erscheinung ein Meteor war. Sie wird auch in der Kreuzzugschronik des Raimond d'Aguilers und bei Hugo von Fleury erwähnt. Siehe ibid. S. 350, Anm. 26.

137 Guibert de Nogent, Dei Gesta, V, 22, S. 224f.: Nocte ergo sequenti ignis species a plaga occidentali de caelo prolabitur ac intra hostilia castra cadendo demittitur. Utrisque partibus spectabile plurimum prebuit casus iste miraculum; at ubi mane inclaruit, quo citius potuere Turci a loco, in quo desederat celestis flamma, recedunt et ante Boemundi quam occupaverat portam castra reponunt. Quod portentum illud quod sibi imminebat patenter, si intellexissent, enuntiare videbatur exitium.

138 Allgemein zum Umgang Guiberts mit seiner Vorlage siehe BöHM, Geschichtsschreibung, S. 98-110. 
Dieser habe anläßlich der Belagerung von Antiochia von einer Himmelserscheinung berichtet, von einem roten Licht, das die Form eines Kreuzes angenommen habe. Dieses Zeichen habe Fulcher als Zeichen der zukünftigen Kämpfe und des Sieges der Kreuzfahrer interpretiert ${ }^{139}$. Guibert merkt darauf an, daß er das Vorzeichen nicht anzweifle, es jedoch unterlassen habe, eine ganz ähnliche Erscheinung bei der oben genannten Aufzählung von Zeichen vor dem Beginn der Unternehmung zu erwähnen. Er wolle sich nicht allzu lange beim Bericht solcher Zeichen aufhalten. Diese Bemerkung auf Guiberts Einschätzung von Vorzeichen auszuwerten, ist schwierig, da Guibert gerade den Berichten von Vorzeichen in Fulchers Chronik oft skeptisch gegenübersteht und somit seine Unterlassung nicht offen eingestehen kann ${ }^{140}$.

Gerade in bezug auf die Erwähnung dieser Himmelszeichen weisen die Handschriften von Guiberts Kreuzzugschronik bemerkenswerte Varianten auf. In zwei Handschriften werden Guiberts Überlegungen zum Zeichen des roten Lichtes im siebten Buch nicht erwähnt, jedoch an anderen Stellen des Berichtes eingesetzt ${ }^{141}$. Einerseits wird es in diesen Handschriften nach der Aufzählung von anderen Vorzeichen vor dem Beginn des Kreuzzuges eingefügt. Dies nicht ohne Grund: Guibert merkt in der Passage aus dem siebten Buch an, er habe vergessen, ein ähnliches Zeichen dort zu erwähnen. Andererseits ist das Zeichen in den Bericht der Belagerung von Antiochia eingeflochten, dort, wo Guibert erwähnt, daß es Fulcher berichtet habe ${ }^{142}$. Dies an der Stelle, wo Pyrrus, der türkische Verräter, eingeführt wird, der den Ausschlag zur Eroberung von Antiochia gab ${ }^{143}$.

An beiden Stellen der Handschrift steht der Bericht des Zeichens in einer Randnotiz. Dies ist ein Hinweis auf das Vorgehen des Schreibers: Als er während der Abschrift seiner Vorlage bei der Stelle im siebten Buch angekommen war, beurteilte er den Bericht dieser Zeichen als wichtig und fügte sie nachträglich in den Text ein ${ }^{144}$. Die providentielle Bedeutung dieses Zeichens scheint vom Schreiber dieser Handschrift höher eingeschätzt worden zu sein als von Guibert selber. Dieser verwendet den Bericht über das Zeichen vor allem, um Kritik an Fulcher zu üben, scheint aber, im Gegensatz zu anderen

139 Guibert de Nogent, Dei Gesta, VII, 35, S. $333 \mathrm{f}$.

$140 \mathrm{Vgl}$. dazu unten, S. $195 \mathrm{f}$.

141 Es sind dies die Handschriften Kopenhagen, BR, Fabricius $95,8^{\circ}(\mathrm{K})$ und die verlorene Handschrift Pt, die von François Pithou an den ersten Editor Jacques Bongars entliehen wurde. Guibert de Nogent, Dei Gesta, S. 29-34.

142 Fulcher von Chartres, Historia, I, 15, 16.

143 Siehe dazu HeERs, Libérer Jerusalem, S. $193 \mathrm{f}$.

144 Dies auf fol. 41v und fol. 87r der Handschrift K. Diese nicht unwichtige Korrektur der Bedeutung der Vorzeichen gegenüber Guiberts distanzierter Verwendung derselben zeigt, wie wichtig es ist, Variationen verschiedener Handschriften zu beachten. Varianten und Beweglichkeit von Textpassagen wurden von den Vertretern der "New Philology in Abgrenzung von der klassischen philologischen Methode in den Mittelpunkt der Betrachtung gestellt. Eine moderate Einordnung dieser Ansätze bei Wolf, New Philology. 
Chronisten, der Geschichte des Verräters Pyrrus keinen großen Stellenwert einzuräumen ${ }^{145}$.

Wundererzählungen als Elemente ironischer Distanzierung, als Beweise und als lehrreiche Beispiele

Guibert stellt seiner Überarbeitung des anonymen Kreuzzugsberichts ein einführendes Buch voran. Er erweist sich damit als Gelehrter, der zu Beginn seiner Chronik die Umstände der Expedition beschreibt. So vergleicht er den Kreuzzug mit antiken Kriegen, beschreibt das griechische Schisma, die Ausbreitung des Islam und stellt auch das Leben und die Lehre Mohammeds vor $^{146}$. In die letztere Beschreibung fügt Guibert eine Wundererzählung ein. Dabei beklagt er, daß ihm im Gegensatz zur Einordnung christlicher Häresien autoritative Schriften der Kirchenväter fehlten, in denen diese neue »Häresie« beschrieben sei ${ }^{147}$. Diese fehlende Erwähnung ist für Guibert der einzige chronologische Anhaltspunkt, sozusagen der terminus post quem, zur Einordnung des Lebens Mohammeds ${ }^{148}$. So gibt er als Quelle seiner Darstellung von Leben und Lehre des Mohammed einzig die mündliche Überlieferung an ${ }^{149}$. Im Laufe einer abenteuerlichen Konstruktion über das Leben des Propheten Mohammed berichtet Guibert das miraculum der Offenbarung der islamischen heiligen Schrift als Betrug des Mohammed, inspiriert von Dämonen ${ }^{150}$. So habe Mohammed die Schriftrolle einer dressierten Kuh auf die Hörner gebunden und die Kuh so versteckt, daß sie dem Propheten im richtigen Moment mit der Schriftrolle entgegen rannte ${ }^{151}$. Die unterstellte Interpretation des Ereignisses als Wunder durch die Anhänger Mohammeds gibt diese der Lächerlichkeit preis. Die Unterstellung der Leichtgläubigkeit der Anhänger der angegriffenen feindlichen Glaubensgemeinschaft dient der Diskreditie-

145 Vgl. dazu Levine, Pious Traitor, S. 73.

146 Guibert De Nogent, Geste, Introduction, S. 16f. Dazu D'Ancona, Leggenda di Maometto, S. 46; Alverny, Pierre le Vénérable; Southern, Western Views, S. 28-32; Flori, caricature de l'Islam, hier S. 253f.; CoLE, O God, S. 97-100.

147 Bei der Einordnung der Häretiker von Soissons konnte Guibert, wie allgemein üblich, auf die Beschreibungen des Augustin zurückgreifen. Siehe GuiberT DE Nogent, Autobiographie, III, 17, S. 430.

148 Siehe LetTNick, Comment les historiens, S. $58 \mathrm{f}$.

149 Guibert de Nogent, Dei Gesta, I, 3, S. 94: Quem prophanum hominem parvae multum antiquitatis existimo, non ob aliud scilicet nisi quia aecclesiasticorum doctorum neminem contra eius spurcitiam scripsisse repperio. Cuius mores vitamque cum nusquam scripta didicerim, quae a quibusdam disertioribus dici vulgo audierim nulli debet esse mirum si dicere velim. RotTer, Embricho, S. 82 und passim, stellt wiederholt Verbindungen von Guiberts Darstellung mit dem als Vita Mahumeti bekannten Gedicht her, das Embricho von Mainz zwischen 1072 und 1090 verfaßt haben soll. Ob Guibert Embrichos Vita Mahumeti gekannt hat, sich seine Kenntnisse aus unterschiedlichen Quellen zu Mohammed erarbeitet hat oder ob er sich auf mündliche Pilger- oder Kreuzfahrerberichte beruft, ist nicht geklärt.

150 Guibert DE Nogent, Dei Gesta, I, 4, S. 98.

151 Siehe zur Interpretation dieses Abschnitts auch RubENSTEIN, Guibert of Nogent, S. $121 \mathrm{f}$. 
rung derselben. Weiter unten im Text relativiert Guibert denn auch diese Konstruktion als Scherz und bietet eine neutralere Version seiner Interpretation des islamischen Glaubens ${ }^{152}$. Das konstruierte Wunder hat in der Geschichte neben der Darstellung des schmählichen Todes des Propheten die Funktion eines dramatischen Höhepunktes ${ }^{153}$.

Im Anfangsteil des zweiten Buchs, den Guibert auf ähnliche Weise wie im ersten Buch der überarbeiteten Chronik vorangehen läßt, stellt er die Protagonisten und Teilnehmer des Kreuzzugs vor. Als erster wird der Initiator des Kreuzzuges, Papst Urban II, eingeführt. Auch dieser Abschnitt ist eine Ergänzung der Vorlage Guiberts. So verweist Guibert auf Zeugnisse, die von Wundern am Grab des Papstes berichten. Das eine Wunder, das Guibert in seinem Bericht wiedergibt, soll laut Kommentar von den Tugenden des Papstes zeugen. Die Erzählung handelt von einem jungen Mann, der bei dem Verlust seiner Glieder wettet, daß an diesem Grab niemals Wunder geschehen werden. Auf der Stelle verliert er seine Sprache, wird halbseitig gelähmt und stirbt innert dreier Tage ${ }^{154}$. Die Wundererzählung dient hier, im Gegensatz zur vorher genannten, auf ernsthafte Weise der Verehrung des verstorbenen Papstes, des Initiators des Kreuzzuges. Die beiden Wunder, die in den einleitenden Partien des Berichts eingefügt sind, untermalen Guiberts Rollenverteilung für seine Chronik: Während im Lager der Feinde Wunder nur Lug und Trug sind, wirkt Gott am Grab des Initiators der Unternehmung Wunder und offenbart dadurch seine Präsenz.

Weitere Erzählungen finden sich im zweiten, wiederum von der Vorlage unabhängigen Teil des siebten Buchs. Hier setzt Guibert Wundererzählungen dazu ein, den Kreuzzugsbericht Fulchers von Chartres, auf den er in diesem Kapitel eingeht, zu diskreditieren ${ }^{155}$. In dieser Absicht verwendet er die Erzählung über eine Gruppe von Kreuzfahrern, die auf der Überfahrt von Apulien nach Griechenland Schiffbruch erlitten. Ihre Leichen hätten, an Land geschwemmt, alle ein Kreuz auf die Schulter tätowiert gehabt ${ }^{156}$. Guibert nimmt diese Erzählung, für die er Fulchers Chronik als Quelle angibt, zum Anlaß, vor Mißbräuchen zu warnen. An gleicher Stelle weist Guibert auf den früher in der Chronik eingeführten Bericht des Mißbrauchs durch einen Abt, der sich ein Kreuz auf die Stirn gemalt hat und behauptet, ein Engel habe ihm dieses Kreuz in einer Vision eingraviert ${ }^{157}$. Die Kritik an Fulcher äußert Guibert in

152 Guibert de Nogent, Dei Gesta, I, 4, S. 100: Sed omissis iocularibus quae pro sequacium derisione dicuntur, [...]. Zu den rhetorischen Vorlagen dieser Rücknahme der ersten, satirischen Darstellung siehe Levine, Satiric vulgarity, S. $272 \mathrm{f}$.

153 Eine Einordung der Mohammed-Episode bei Levine, Satiric vulgarity. Er stellt die Darstellung des schmählichen Todes - der Prophet wird von Schweinen aufgefressen - in die klassische Tradition der Invektive, worin das Bild der Schweine eine große Rolle spielt.

154 Guibert de Nogent, Dei Gesta, II, 1, S. 107.

155 Siehe dazu BöнM, Geschichtsschreibung, S. 122.

156 Guibert de Nogent, Dei Gesta, VII, 32, S. 329 f. Siehe oben, S. 141 und S. $159 f$.

157 Guibert de Nogent, Dei Gesta, IV, 17, S. 197. 
seinem Vorwurf, daß dieser als Verfasser einer Chronik nicht genügend kritisch mit der wunderbaren Geschichte umgegangen sei. Sogleich führt er als Beispiel seiner kritischen Beurteilung an, wie eine Menschenmenge in Beauvais einen Wolkenturm als Zeichen des Kreuzes interpretiert habe, er hingegen habe die Form eher als Kranich oder Schwan gedeutet ${ }^{158}$. An diese Erzählung fügt Guibert die Geschichte einer Frau mit ihrer Gans an. Diese habe sich mit einer Gans auf den Weg nach Jerusalem gemacht. Das Gerücht ging, daß die Gans die Frau auf wunderbare Weise führte. Das Tier soll jedoch in Lothringen gestorben sein, was Guibert mit einer ironischen Bemerkung kommentiert: »...diese wäre auf direktem Weg nach Jerusalem gekommen, wenn sie sich am Tag vor der Abreise ihrer Herrin als Festschmaus dargeboten hätte ${ }^{159}$. Diese fabula führt Guibert seinem Bericht als Warnung an, die Ernsthaftigkeit christlicher Geschichte auf keinen Fall dadurch zu gefährden, daß volkstümlichen Fabeln Glauben geschenkt werde ${ }^{160}$. Diese Belehrung kann wieder als indirekter Vorwurf an Fulcher gelesen werden.

Ein weiteres Mal wird im siebten Kapitel eine Wundererzählung im Zusammenhang mit anderen Argumenten verwendet, um der Chronik des Fulcher zu widersprechen. Fulcher gehörte, im Gegensatz zu Guibert, zu denjenigen, welche die Echtheit der heiligen Lanze bezweifelten. Neben der Erwähnung von Augenzeugen und einem Brief des Balduin von Edessa an Manasses von Reims zieht Guibert eine Wunderepisode als Beweis der Echtheit der heiligen Lanze heran. Die Lanze habe zugunsten des Bischofs von Le Puy in einer Schlacht den Rauch vertrieben, den die Gegner durch Anzünden des Grases provoziert hätten ${ }^{161}$.

Andererseits steht ebenfalls im siebten Kapitel eine Dämonenerzählung als Exkurs, außerhalb des ironisch-kritischen Zusammenhangs, in welchen der Großteil der Wundererzählungen gestellt werden kann. Die Erzählung - ein Ritter wird vom Teufel, von dem er Hilfe angenommen hat, befreit - dient der Erbauung des Lesers und wird als Exemplum dafür eingeführt, welch gute Wirkung ein Entschluß für die Teilnahme am Kreuzzug haben kann. Zudem verdeutlicht die Erzählung, was Beichte und Buße vermögen. Als Schlußfolgerung setzt Guibert die Überlegung, welche Wohltat der Kreuzzug für reine Herzen sei, wenn sie schon unreine auf solche Weise bewege ${ }^{162}$. Diese Erzählung, als erbauliches Exemplum in den Bericht eingefügt, erinnert an die Art, wie die Wundererzählungen in den Monodiae als lehrreiche Erzählungen mit

158 Ibid. VII, 32, S. 330.

159 Ibid. VII, 32, S. 331: [...]; qui sane Iherusalem rectius isset, si pridie quam proficisceretur suae seipsum dominae festa convivia prebuisset.

${ }_{160}$ Ibid. VII, 32, S. 331: Quod totum ob hoc a nobis Historiae veraci attexitur, ut se noverint quique commonitos quatinus nequaquam, fide vulgi fabulis attributa, christiana gravitas levigetur.

161 Ibid. VII, S. 332f.; dazu BöHM, Geschichtsschreibung, S. 124f.

162 Guibert de Nogent, Dei Gesta, VII, 30, S. 323-327. 
einer analysierenden Schlußfolgerung verwendet werden. Guibert legt die Quelle dieser Erzählung nicht offen.

Guibert übernimmt einen weiteren Wunderbericht aus Fulchers Bericht, ohne einen kritischen Unterton anzuschlagen, entwickelt ihn jedoch weiter. Es ist dies die Geschichte einer Lampe in der Grabeskirche, die sich alljährlich am Karsamstag selbst entzündet. Die Ungläubigen in der Stadt haben diesem Wunder mißtraut und sind mit Schwertern bewaffnet in die Kirche eingedrungen, um zu überprüfen, ob das Wunder durch Betrug oder durch den Glauben der Christen geschehe. Das Wunder findet dann pünktlich statt. $\mathrm{Zu}$ anderen Gelegenheiten läßt es auf sich warten, das Ereignis kehrt aber doch alljährlich wieder ${ }^{163}$. Von seiner Vorlage weicht Guibert insofern ab, als er nicht wie Fulcher ein Ereignis darstellt, sondern deren drei. Drei Elemente von Fulchers Erzählung ordnet er je einem wunderbaren Ereignis zu. So entwickelt er im Bericht über das erste Wunder Fulchers die kurze Erwähnung von Ungläubigen, welche die Christen mit dem Tode bedrohen, weiter. Daß diese kontrollieren, ob das Wunder Betrug sei, ist nur in Guiberts Bericht vermerkt ${ }^{164}$. In seinem Bericht des zweiten Ereignisses führt die Beichte und die Versöhnung der Gläubigen dazu, daß die Lampe sich entzündet ${ }^{165}$. Fulcher berichtet zu Beginn der Erzählung ebenfalls, daß die Gläubigen Buße getan hätten, dies führt in seiner Version aber noch nicht zum Wunder ${ }^{166}$. Auch im Falle der dritten Geschichte geht Guibert auf gleiche Weise vor: Fulchers Bericht, daß er von der Grabeskirche zum Kalvarienberg gestiegen ist, um zu prüfen, ob das Wunder sich dort ereignet hat, entwickelt Guibert zu einer eigenen Erzählung, läßt Fulcher aber auf den Ölberg steigen.

Zwei Themen, die in Guiberts Werken wiederholt eine Rolle spielen, werden in seiner Version des Wunders betont: Der Einfluß von Beichte und Reue und die Frage nach betrügerischen Wundern. Die Frage nach dem betrügerischen Hervorrufen des Wunders, die Guibert hier die Ungläubigen stellen läßt, handelt er später im Reliquientraktat als wichtiges Thema ab.

In der Kreuzzugschronik Dei Gesta per Francos sind die Wundererzählungen auf diejenigen Teile konzentriert, die Guibert seiner Vorlage hinzugefügt

163 Ibid. VII, 41f., S. 340-343. Die Erzählung findet sich in der Version des Codex L des Fulcher von Chartres: Fulcher von CharTres, Historia, S. 831-834. Zu den Rückschlüssen, die aufgrund dieser Stelle auf den Zusammenhang der verschiedenen Fassungen der Berichte von Guibert und Fulcher gezogen werden, siehe Huygens, Tradition manuscrite, S. 38f.

164 GuIBert dE Nogent, Dei Gesta, VII, 41, S. 341: Erat autem eadem moris in urbe ut circumitis pagani universorum edibus singularum focos usque ad favillas extinguerent, et tanta id fiebat ab ethnicis indagine, quantum idipsum putabatur fieri fidelium fraude, non fide. [...] vidisses per universam gentiles exertis mucronibus oberrare basilicam mortemque nostrorum quibusque minari; FULCHER vON CHARTRES, Historia, S. 832: quia si in uno anno deficeret quin veniret, protinus a paganis hoc explorantibus et inquirentibus omnes decollarentur.

165 Guibert de Nogent, Dei Gesta, VII, 42, S. 342.

166 Fulcher von Chartres, Historia, S. 832. 
hat, auf das erste, den Anfang des zweiten und vor allem auf das siebte Buch. $\mathrm{Zu}$ den Himmelserscheinungen, die Guibert in Überarbeitung seiner Vorlage innerhalb des Ablaufes des Kreuzzugs nennt, fügt er in jedem Fall Erörterungen über die Einordnungsmöglichkeiten dieser Erscheinungen hinzu. Diese sind in seiner Vorlage nicht verzeichnet.

Guibert setzt in seinem historischen Werk Wundererzählungen auf verschiedenste Weise ein. Sie stellen Möglichkeiten dar, ironische Kommentare zu bieten, aber auch Kritik zu üben oder als Argumente zu dienen. Wundererzählungen werden aber auch als erbauliche Exempla eingesetzt und in ernsthafter Weise übernommen, wenn sie Guiberts Kriterien entsprechen und einen Beweis des Glaubens der Christen darstellen. 


\subsection{Einsatz von Wundererzählungen in Guiberts Texten}

Die Analyse der Stellung und Funktion der Wundererzählungen in Guiberts Texten hat die Vielfalt der Funktionen gezeigt, welche die Erzählungen erfüllen können. In der Kreuzzugschronik sind sie sehr unterschiedlich. Sie spielen in diesem historischen Text allerdings eine umfangmäßig wie inhaltlich geringe Rolle. Eine Leitidee der Darstellung, die mit Hilfe der Wundererzählungen vermittelt werden soll, ist nicht zu erkennen. In der autobiographischen Schrift, den Monodiae, spielen Wundererzählungen hingegen eine wichtige Rolle. Als exemplarische Exkurse sind sie Träger von Aussagen des Textes, entweder als Variationen zu den Stationen und Brüchen von Guiberts eigener Geschichte oder als Beispiele von verschiedensten Verhaltensweisen. Wundererzählungen sind in diesem Text als didaktische Exempla eingesetzt. Im Reliquientraktat, der bezüglich seines Inhalts am engsten mit der Thematik Wunder und Reliquienkult verbunden ist, stellen Wundererzählungen ebenfalls Beispiele dar, hier jedoch innerhalb einer argumentativen Abhandlung, die sich in kritischem Ton zu diesen Themen äußert. Im Marienlob, einem Traktat zur Marienverehrung, sind Wundererzählungen in einem Block eingefügt und stellen neben der biblischen Geschichte Zeugnisse der Größe Mariens dar. Diese sind am ehesten als Predigtexempla zu betrachten, wie auch ihre weitere Überlieferung in Marien- und Exemplasammlungen zeigt.

So wie einzelne Themen wie Buße, Beichte oder Verehrung als Aussage der Wundererzählungen in den verschiedenen Werken immer wieder erwähnt werden, wird eine Gruppe von Wundererzählungen in mehreren Werken eingefügt.

An erster Stelle ist das Edmund-Wunder zu nennen ${ }^{167}$. Wie oben dargestellt, wird es sowohl in den Monodiae als auch im Reliquientraktat erwähnt. Der Zusammenhang und die Deutung der Erzählung sind in den zwei Werken aber unterschiedlich. Steht die Episode in den Monodiae in einer Gruppe von Erzählungen, welche die Größe und Kraft von Heiligen zeigen soll, ist sie im Reliquientraktat neben Zitaten aus der Bibel und den Kirchenvätern Teil einer Argumentation, welche die Mißachtung der Grabesruhe von Heiligen anprangert ${ }^{168}$. Dieses Thema der Grabesruhe, die gewahrt werden soll, wird schon in der Kreuzzugschronik erwähnt. Dort ist der Ausgangspunkt der Argumentation der Kopf Johannes' des Täufers. Von diesem Kopf behaupteten die Mönche von Saint-Jean-d'Angély, daß sie ihn besäßen ${ }^{169}$. Gleichzeitig soll dieser Kopf in Konstantinopel aufbewahrt worden sein. Dieses Beispiel wird, immer mit der Bemerkung, daß Johannes der Täufer nicht doppelköpfig gewesen sein könne, zuerst in der Kreuzzugschronik ${ }^{170}$, dann auch in der Reli-

167 Siehe oben, Kap. 3.2.3.

168 Siehe zur Episode in den Monodiae oben, S. 172; im Reliquientraktat oben, S. 181.

169 Guibert de Nogent, Dei Gesta, I, 5, S. 103f. Siehe dazu oben, S. 68.

170 Guibert de Nogent, Dei Gesta, I, 5, S. 103. 
quienkritik erwähnt ${ }^{171}$. Die Wiederverwendung dieses Abschnittes aus der Kreuzzugschronik zeigt, wie Guibert einen Gedanken aus dem älteren Werk wiederaufnimmt, in neuem Zusammenhang weiterentwickelt und mit neuen Exempla versieht.

Ein weiteres Beispiel für die Wiederverwendung einer Wundererzählung ist die Episode der Heilung eines Krüppels durch Vespasian. Dieses Beispiel ist sowohl im Reliquientraktat als Beispiel für einen heidnischen Mittler, dessen Glaube nicht der Auslöser seiner Wundertätigkeit gewesen sein konnte, als auch im Marienlob verwendet ${ }^{172}$. Dort wird das Beispiel dazu eingesetzt, um zu zeigen, wie bewußt die Gottesmutter Maria Jesus durch den heiligen Geist empfangen hat. Auch die biblischen Beispiele vom Esel des Bileam und vom Hohepriester Kaiphas werden in beiden Texten verwendet ${ }^{173}$.

Mehrfachverwendungen und Verknüpfung von Exempla mit verschiedenen Deutungsebenen sind im Mittelalter üblich ${ }^{174}$. Guibert verfährt nicht nur mit Wundererzählungen, sondern auch mit anderen Textelementen auf ähnliche Weise. So erzählt er einen Traum seines Lehrers in den Monodiae und im Widmungsbrief zu seinem Traktat Contra judaizantes et judeos. Den Anlaß des Traums, Guiberts Verfassen von bukolischen Gedichten, erwähnt er in den Monodiae und im nachträglich verfaßten Widmungsbrief zu seinem Erstlingswerk De virginitate ${ }^{175}$.

Wundererzählungen haben in den Werken Guiberts de Nogent hauptsächlich drei Funktionen. Erstens dienen sie der Belehrung seines Publikums. Sie sind Lehrstücke, anhand derer Guibert eine Lektion erteilen will. Diese Lehrstücke drehen sich um immer wiederkehrende Themen wie Buße, Beichte und Belohnung einer gläubigen Verhaltensweise, aber auch Strafe von Mißbräuchen oder Mißachtung der kirchlichen Autorität. Zweitens funktionieren sie als Argumente zur Verdeutlichung eines Gedankenganges oder als Bestandteil einer längeren Argumentation. Zum dritten können sie auch dazu eingesetzt werden, Distanzierung zum Erzählten zu markieren und werden somit in ironischer Weise verwendet. Wundererzählungen können auch, selbst wenn sie wie bei Guibert außerhalb von hagiographischen Texten in engerem Sinne stehen, der Verehrung von Heiligen dienen.

171 Guibert de Nogent, Quo ordine, P, I, Z. 533-549.

172 Siehe dazu oben, S. 52.

173 Siehe dazu oben, S. 44.

174 Moos, Geschichte, S. 342, 358f.

175 Siehe oben, S. 21. 